\title{
La segregación urbana desde el tiempo y el espacio. Una aproximación en una ciudad patagónica (Neuquén, 1904-2010) ${ }^{1}$
}

\section{Urban segregation from time and space. An approximation to a Patagonian city (Neuquén, 1904-2010)}

\author{
Joaquín Perrén \\ Universidad Nacional del Comahue; \\ Consejo Nacional de Investigaciones Científicas y Técnicas (Argentina) \\ joaquinperren@gmail.com
}

Germán Pérez

Instituto Patagónico de Estudios de Humanidades y Ciencias Sociales Consejo Nacional de Investigaciones Científicas y Técnicas (Argentina)

germanp80@gmail.com

\begin{abstract}
Resumen
La diferenciación espacial ha sido unos de los rasgos más duraderos de la vida urbana y su estudio ha sido un foco de interés para las ciencias sociales. Con todo, el grueso de la literatura especializada ha tenido a las áreas metropolitanas como escenarios dilectos de sus indagaciones, algo que se recrudece en el caso de América Latina debido a su secular tendencia a la macrocefalia. Además de focalizarse en las grandes ciudades, al punto de asimilar el estudio de una parte con el todo, los trabajos interesados en el estudio de la segregación residencial se han detenido mayormente en el presente. Un rápido repaso de la producción reciente sobre esta temática nos alertaría sobre la existencia de una más que evidente asimetría: la abundancia de estudios sociológicos, antropológicos y geográficos contrasta con la escasez de trabajos elaborados dentro de los límites de la historia. El presente artículo nace de la voluntad de colaborar en la cobertura de las dos lagunas de conocimiento que se desprenden del balance que acabamos de realizar. En lugar de centrar nuestra atención en una de las muchas áreas metropolitanas de la región, nos detendremos en una aglomeración de tamaño intermedio: Neuquén, en la Norpatagonia argentina. Al mismo tiempo, y con el propósito de morigerar el sesgo presentista que ha atravesado la literatura sobre la segregación, privilegiamos una aproximación al siglo XX, recorriendo tres etapas claramente delimitadas: el "Neuquén territoriano" (1904-1955), "el Neuquén desarrollista" (1955-1990) y el "Neuquén neoliberal" (1990-2010). En cada una de estas etapas veremos los principios que modelaron la estructura urbana neuquina y los patrones de segregación que emergieron de la misma. En términos metodológicos, el trabajo se nutre de una amplia gama de fuentes, desde documentación nominativa hasta datos censales, sistematizada y organizada mediante el uso intensivo de Sistemas de Información Geográfica.
\end{abstract}

${ }^{1}$ El presente trabajo se enmarca dentro del Proyecto Unidades Ejecutoras (IPEHCS - CONICETUNCo) titulado "La (re)producción de las desigualdades en la Patagonia Norte. Un abordaje multidimensional" (22920180100046CO).

Esta obra está sujeta a la Licencia Reconocimiento-NoComercial-CompartirIgual 4.0 Internacional de Creative Commons. http://creativecommons.org/licenses/by-nc-sa/4.0/

(cc) $\mathrm{EY}-\mathrm{NC}-\mathrm{SA}$ 
Joaquín Perrén - Germán Pérez

\title{
Palabras clave
}

Segregación; Desigualdad; Estudios Urbanos; Historia Regional; SIG

\begin{abstract}
Spatial differentiation has been one of the most lasting features of urban life and its study has been a focus of interest for the social sciences. After all, most of the specialized literature has had the metropolitan areas as attractive scenarios for its investigations, something that is exacerbated in the case of Latin America due to a secular tendency towards macrocephaly. In addition to focusing on large cities, to the point of assimilating the study of a part with the whole, the works interested in the study of residential segregation have mostly stopped in the present. A quick review of recent production on this subject would alert us to the existence of a more than obvious asymmetry: the abundance of sociological, anthropological and geographical studies contrasts with the scarcity of works produced within the limits of history. This article is born from the desire to collaborate in the coverage of the two knowledge gaps that arise from the balance that we have just made. Instead of focusing our attention on one of the many metropolitan areas of the region, we will stop at an intermediate-sized agglomeration: Neuquén, in the northern part of Argentine Patagonia. At the same time, and with the purpose of mitigating the presentist turn that the literature on segregation has gone through, we privileged an approximation to the 20th century, going through three clearly delimited stages: "Territorial Neuquén" (1904-1960), "Developmentalist Neuquén"(1960-1990) and "Neoliberal Neuquén" (1990-2010). In each of these stages we will see the principles that modeled the urban structure of Neuquén and the patterns of segregation that emerged from it. In methodological terms, the work draws from a wide range of sources, from nominative documentation to census data, systematized and organized through the intensive use of Geographic Information Systems.
\end{abstract}

\section{Keywords}

Segregation; Inequality; Urban Studies; Regional History; GIS 


\section{La segregación urbana desde el tiempo y el espacio. Una aproximación en una ciudad patagónica (Neuquén, 1904-2010)}

\section{Introducción}

Hace ya diez años, Ananya Roy publicaba un artículo que hizo las veces de revulsivo dentro del campo de los estudios urbanos. Con una pluma incisiva y una enorme erudición, la urbanista de origen indio llamaba la atención sobre la insuficiencia de "estudiar las ciudades del Sur global como interesantes casos empíricos anómalos, diferentes y esotéricos" (Roy, 2009 [2012]: 151). Este tipo de enfoques no habían hecho más que interpretar a "las ciudades del Tercer Mundo como el corazón de las tinieblas, lo Otro" (Roy, 2009 [2012]: 151). Para revertir esa tendencia era necesario un dislocamiento que permitiese una "calibración de las geografías del conocimiento autorizado" y la producción de "una nueva serie de conceptos en el crisol de un nuevo repertorio de ciudades" (Roy, 2009 [2012]: 152). De esta manera podrían lograrse un conjunto de reflexiones que fuesen, a la vez, localizadas y deslocalizadas. Localizadas porque tienen que "ser producidas en lugares (e importa dónde se producen)" y deslocalizadas porque "luego éstas pueden ser objeto de apropiación, préstamo y reasignación” (Roy, 2009 [2012]: 152). Así, las experiencias distintivas de las ciudades de los países del Sur global pueden generar marcos teóricos productivos y provocadores para todas las ciudades.

Estos consejos pueden aplicarse sin problemas al estudio de la diferenciación socioespacial, en general, y al de los patrones de segregación, en particular. Llevando al extremo la propuesta de Roy, el presente trabajo podría pensarse como un ejercicio de triple dislocamiento. El primer desplazamiento es el que parece más obvio: tomando distancia de las ciudades globales clásicas, tan bien estudiadas por Saskia Sassen (1991), proponemos una mirada que atienda a las particularidades que asumió la urbanización en América Latina. El segundo corrimiento va en el sentido de ampliar la gama de urbes a estudiar. En lugar de centrar nuestra atención en una de las muchas áreas metropolitanas de la región, nos detendremos en una

aglomeración de tamaño intermedio localizada al sur del Sur global: Neuquén, en la Norpatagonia argentina. La tercera frontera que esperamos ensanchar es la que corresponde a la dimensión temporal. Con el propósito de morigerar el sesgo presentista que ha atravesado la literatura sobre la segregación, privilegiamos navegar por las profundas aguas de la larga duración, parafraseando a Fernand Braudel (1970: 64).

Volveremos operativo este triple dislocamiento a partir del estudio de tres etapas claramente delimitadas, a saber: a) el "Neuquén territoriano" (1904-1955), b) "el Neuquén desarrollista” (1955-1990), y c) el “Neuquén neoliberal” (1990-2010). En cada una de estas fases veremos los principios que modelaron la estructura urbana neuquina y los patrones de segregación que emergieron de la misma. Partimos de dos hipótesis que son - a la vez- localizadas y deslocalizadas. La primera de ellas podría sintetizarse en una frase: las ciudades intermedias, muchas veces pensadas desde el prisma de la igualdad, fueron asiento de fenómenos de segregación multiformes y variables en el tiempo. La segunda nos conduce al campo de la producción de ciudad: las urbes de medio rango no necesariamente presentan un 


\section{Joaquín Perrén - Germán Pérez}

carácter compacto, sino que, en ocasiones, exhiben un crecimiento extensivo que intensifica las desigualdades urbanas. Para poner a prueba estos supuestos echaremos mano de una amplia gama de fuentes, entre ellas informes técnicos, artículos periodísticos, documentación nominativa, información censal y cartografías temáticas elaboradas con Sistemas de Información Geográfica.

\section{La segregación bajo la lupa. Un repaso de la literatura enfocada al estudio de las desigualdades urbanas}

La segregación remite a "las formas de desigual distribución de grupos de población en el territorio" (Levy y Brun, 2002). De todos modos, y tomando distancia de la tradición ecológica norteamericana, creemos que descubrir estos grados de distancia no es un fin en sí mismo, sino un medio para acceder a una relación social de poder. Desde esta perspectiva, la segregación solo opera como desigualdad cuando es resultado de una restricción a la localización impuesta por un grupo por sobre otros. Este tipo de limitaciones eran evidentes a simple vista en aquellas sociedades en las que la discriminación étnica poseía un estatuto legal. Con la desaparición del apartheid, los caminos por los que se abrió paso la segregación se volvieron mucho más sutiles. Las limitaciones a la localización dejaron de estar relacionadas con el color de la piel y se vincularon -directa o indirectamente- a la capacidad adquisitiva de las personas. Los individuos tienen que adaptar sus preferencias a las posibilidades de localización en la ciudad, ya sea adquiriendo (o alquilando) una vivienda que se ajuste a sus ingresos o bien accediendo a la misma por medio de políticas públicas.

Un repaso de la producción dedicada al estudio de la segregación residencial para el caso argentino nos mostraría una indisimulable macrocefalia: el grueso de la literatura disponible posó su mirada en la ciudad de Buenos Aires y su área metropolitana (Torres, 1975; Scobie, 1986; Moya, 2003; Rodríguez, 2008 y Marcos y Mera, 2009). En buena medida tributarios de las tempranas reflexiones de Torres, estos trabajos demostraron la existencia de una configuración en la que se distinguía claramente el contraste entre un centro "rico", que no había sufrido el proceso de deterioro de otras metrópolis latinoamericanas, y una periferia persistentemente "pobre" conformada por una amplia gama de opciones habitacionales, desde barrios obreros planificados hasta asentamientos informales. Gracias a estos estudios, algunos de ellos escritos en clave histórica o geográfica y otros elaborados en los límites de la sociología o la antropología, pudimos saber que ese esquema dual hundía sus raíces en los tiempos dorados del modelo agroexportador, pero también que había experimentado muy interesantes transformaciones al calor de la globalización y del desembarco del neoliberalismo. Entre los trabajos que se focalizaron en el estudio de las novedades que irrumpieron en el área metropolitana bonaerense en los últimos años, podemos mencionar aquellos que se detuvieron en la multiplicación de los espacios residenciales cerrados (Svampa, 2001; Lacarrieu, 2002; Carballo, 2002; Girola, 2008; y Vidal Koppmann, 2007), en la densificación y 


\section{La segregación urbana desde el tiempo y el espacio. Una aproximación en una ciudad patagónica (Neuquén, 1904-2010)}

verticalización del centro tradicional (Ciccolella y Mignaqui, 2009), en la aparición de nuevas centralidades alrededor de sitios de consumo u ocio (por caso, shopping centers, hipermercados o complejos de cines)(Ciccolella y Vecslir, 2012), así como en el reforzamiento de enclaves étnicos en el corazón de la ciudad(Sassone, 2009; Sassone y Mera, 2009).

Junto a este conjunto de trabajos, podemos destacar una segunda línea de indagación, de menor importancia relativa, que intentó testear en urbes de tamaño intermedio distintos modelos que explicaban la segregación en las áreas metropolitanas. Al interior de esta corriente debemos situar los intentos de Cervera (1970) de analizar la ecología de la ciudad de Santa Fe a partir del modelo sectorial de Hoyt (1939) o los de Reñe (1994) de utilizar la plantilla de Griffin y Ford para comprender la configuración espacial de Rosario. En ambos casos, notamos un afán descriptivo que, aunque valioso por su carácter señero, no dejaba de ser un ejercicio deductivo: partiendo de un modelo definido a priori, buscaba las semejanzas que la configuración de aquellas ciudades pampeanas presentaba en relación con el mismo. Este esquema se trasladó desde lo teórico al campo metodológico: distinguimos en estos trabajos una sobrevaloración de las observaciones de campo, dejando de lado el amplio abanico de fuentes a partir del cual podía reconstruirse el proceso de diferenciación socioespacial, desde el análisis de testimonios personales hasta el procesamiento de los datos micro espaciales provistos por los diferentes censos nacionales de población.

En el caso de las localidades de menor envergadura, problemática mucho más cercana a la que motoriza este artículo, es necesario mencionar los sugestivos aportes de Howell (1989). Tomando en consideración tres ciudades del centro de la provincia de Buenos Aires (Tandil, Azul y Olavarría), este autor llegó a la conclusión que el modelo de Griffin y Ford, pese a ser satisfactorio para explicar la distribución de la población en el tablero urbano, presentaba para los casos estudiados algunas particularidades dignas de ser resaltadas: la residencia de la élite, en lugar de estar asentada en las proximidades de la columna comercial, se encontraba en un sector aislado. Al mismo tiempo, Howell descubrió que la transición desde las áreas de madurez hacia los asentamientos periféricos era mucho menos abrupta, lo cual parecía indicar una mejor distribución de la riqueza y menores niveles de segregación residencial. Por último, esta morfología, a diferencia de la sugerida por Ford, asumió la forma de una malla rectangular, lo cual habla muy bien del crecimiento gradual y relativamente planificado de este tipo de ciudades; algo que las diferenciaba tanto de las áreas metropolitanas de la región como de otras aglomeraciones de tamaño intermedio que experimentaron una verdadera explosión demográfica durante la segunda mitad del siglo XX.

No menos importantes fueron los aportes realizados por Buzai(2003). A partir de la aplicación de diversas técnicas de análisis multivariado y de la obtención de índices de segregación, este geógrafo trazó una modelización de la estructura sociohabitacional de la localidad de Luján, en la que resultaban visibles aspectos señalados por Bähr y Mertins (expansión residencial de la elite), Griffin y Ford 
(anillos concéntricos y spine), Ford (división entre centro comercial e histórico, y aparición de centralidades periféricas) y Borsforf (polarización socio-habitacional propia de la tercera etapa de la secuencia propuesta por el autor). Este trabajo sirvió de catalizador a una serie de estudios que, desde diferentes disciplinas e inquietudes intelectuales, realizaron ejercicios similares para otras ciudades de la Argentina. Sin ánimo de ser exhaustivos, podríamos mencionar las exploraciones realizadas para los casos de Tucumán, Córdoba, Tandil, Bariloche, Mar del Plata, Santa Fe, Puerto Madryn, Bahía Blanca y Resistencia (Falcón, 2011. Natera Rivas y Gómez, 2007. Ares y Mikkelsen, 2007. Sánchez, Sassone y Matossian, 2007. Linares y Lan, 2007. Tecco y Valdez, 2006. Natera Rivas, 2005).

Sobre la base de esta cada vez más frondosa literatura, han comenzado a aparecer los primeros -y, por cierto, muy prometedores- estudios comparativos entre diversas ciudades intermedias argentinas, iniciando una práctica que tiene una larga tradición en otros escenarios latinoamericanos y que en la Argentina tenía muy pocos antecedentes ${ }^{2}$. Entre ellos, es justo destacar trabajos que, echando mano de sofisticadas estrategias cuantitativas, estudiaron la diferenciación socioespacial de diferentes capitales de provincia (Natera Rivas, 2006), de las mayores ciudades de la Pampa Húmeda (Gómez y Natera Rivas, 2012) o de dos áreas metropolitanas sudamericanas (Córdoba, en Argentina, y Campinas, en Brasil) (Peláez, González y Pinto da Cunha, 2008). Bastante más cercano en el tiempo, podemos señalar los estudios de Malizia, Boldrini y Ruíz Peyré (2018), quien -generando una interesante sinergia entre historia, sociología y geografía- han examinado los patrones de segregación de Tucumán y Jujuy, dos ciudades intermedias localizadas en el Noroeste argentino.

Concentremos ahora nuestra atención en el joven campo científico norpatagónico. Una revisión de la producción disponible es suficiente para percibir la escasez y discontinuidad que caracterizan a sus estudios urbanos. Una referencia ineludible en esta área son los pioneros estudios de César Vapnarsky y Edith Pantelides (1983; 1987) sobre el crecimiento urbano y la expansión de diversas ciudades de las provincias de Rio Negro y Neuquén. Sus pesquisas buscaron desentrañar la relación entre una economía regional recostada en la fruticultura y la consolidación de un área metropolitana sin metrópolis: diferentes ciudades estaban físicamente separadas, pero funcionaban de forma interrelacionada, cumpliendo en su conjunto funciones que normalmente aparecían concentradas en urbes de mayor envergadura. Junto a ello, ambos autores introdujeron en sus investigaciones una dimensión temporal: lejos de mantenerse incólume con el paso del tiempo, esta particular configuración experimentó algunos cambios de importancia. Entre ellos, los estudiosos distinguían una clara tendencia hacia la "metropolización" de la capital neuquina en tanto nodo principal del sistema urbano del Alto Valle,

\footnotetext{
${ }^{2}$ Es el caso de México que posee una vasta trayectoria en lo que a estudios comparativos se refiere. Sin ánimos de ser exhaustivos, podríamos señalar los trabajos de Rucalva y Schteingart (2012) y el Álvarez de la Torre (2011) sobre más de treinta ciudades intermedias.
} 


\section{La segregación urbana desde el tiempo y el espacio. Una aproximación en una ciudad patagónica (Neuquén, 1904-2010)}

rompiendo ese equilibrio entre diversas ciudades que había prevalecido en las décadas centrales del siglo XX.

El estudio de las transformaciones urbanas en el ámbito norpatagónico también fue abordado desde la geografía, sobre todo por aquella vertiente que hizo propios los planteos de Milton Santos. Al interior de este campo disciplinar, advertimos, con el final de la última dictadura militar, la puesta en marcha de diversos proyectos de investigación que avanzaron en dos direcciones que, aunque diferentes, tuvieron más de un punto en contacto: por un lado, buscaron realizar un relevamiento de los usos del suelo en la ciudad de Neuquén a fin de analizar la estructura urbana de la ciudad de Neuquén(Goycochea, 1984); mientras que, por otro, confeccionaron cartas de ofertas medioambientales para algunas de las urbes que daban vida al sistema urbano regional (Sinigojet al, 1982, Sinigojet al, 1984 y Colantuonoet al, 1987). También al interior de la geografía, pero en clave más bien ensayística, debemos apuntar los trabajos de Florinda Sznol, especialmente aquellos que versaron sobre las fracturas espaciales que Neuquén experimentó bajo los efectos del neoliberalismo y sobre las formas en que se espacializó la protesta social en tiempos de retroceso del Estado (Sznol, 2007 y 2007a). Con todo, y pese a su carácter multiforme, es posible reprochar a las producciones geográficas, como oportunamente lo hicieran Padín y Perren, "la carencia de perspectiva temporal y falta de historicidad a sus abordajes, como la excesiva quietud de los frescos elaborados, propios de enfoques sincrónicos de las estructuras urbanas" (Padín y Perren, 2015) 3 .

El panorama no es mucho más alentador en el campo de la historia. En un virtual desierto de producción, podemos destacar un trabajo que, pese a tener algunos años, no muestra todavía señales de envejecimiento. Nos estamos refiriendo al libro La ciudad del viento... Historias, Arquitectura y Sociedad en el núcleo urbano de Neuquén Capital, empresa editorial que nació como desprendimiento de un proyecto de extensión de la Universidad Nacional del Comahue y cuya autoría corrió por cuenta, entre otros, de Enrique Mases y Liliana Montes Le Fort (2001). Más allá de ser un texto aislado, que lamentablemente no funcionó como catalizador de una línea de investigación dedicada a la historia urbana de la Norpatagonia, podemos destacar dos méritos. Por un lado, el libro muestra una vocación interdisciplinaria entre la historia y la arquitectura, dando forma a una colaboración que no resulta demasiado habitual ni siquiera en los campos académicos de mayor tradición del país. Por el otro, en el terreno más empírico, el texto, apoyado en un intenso trabajo de archivo y en la revisión de los pocos antecedentes disponibles, nos muestra con lujos de detalles la morfología inicial de la ciudad de Neuquén.

Los festejos por el centenario de la capitalidad, en 2004, fueron un momento propicio para efectuar miradas que atendieron simultáneamente a la necesidad de una producción científica sistemática y al imperativo de transferir conocimiento a la

\footnotetext{
${ }^{3}$ La excepción en este sentido es el trabajo de María Silveira (1988), un estudio pionero sobre los usos del suelo urbano neuquino
} 
sociedad que sirve de soporte a la educación superior. De este cruce de lógicas, lamentablemente no siempre compatibles entre sí, emergió una serie de textos que, aunque nacidos en el ámbito universitario, tuvieron una repercusión que excedió holgadamente el siempre estrecho público académico (Mases et al, 2004; Iuorno, 2004; y Prislei, 2004). Con tiradas cuyos ejemplares se contaron por miles, estos proyectos dotaron la historia de la ciudad de una densidad analítica que, hasta allí, no había tenido, sobre todo a partir del deseo de incluirla en tendencias de mayor alcance espacial. Todo ello, sin perder de vista la relevancia social de reconstruir las biografías de los personajes ilustres de la localidad. Así, entre agudos análisis de la realidad urbana, fotografías inéditas y detalles curiosos de la vida de frontera, se produjo un salto cualitativo en relación con esa tradición descriptiva, con un fuerte aroma a crónica, que había prevalecido en la previa al "Centenario" de la ciudad.

Aunque este grupo de trabajos dio una bocanada de aire fresco a los estudios urbanos de la Norpatagonia, no podemos dejar de señalar dos aspectos que, aunque operan en planos diferentes, están íntimamente relacionados. En primer lugar, por una cuestión de disponibilidad de producción de base, estos libros dieron mayor atención a la etapa territoriana (1904-1958) que a la provincial (1958-2004): el detallado análisis del caserío del novecientos, catapultado al estatus de mito de origen, opacó el estudio de las particularidades que asumió la urbanización neuquina durante la segunda mitad del siglo XX. Y de este desequilibrio se desprende el segundo elemento que podemos ubicar en el casillero del debe: la pronunciada expansión de la ciudad, esa que se dio en la segunda mitad del siglo XX, fue estudiada de manera superficial. La ciudad capital, convertida en una metrópolis de más de doscientos mil habitantes, fue presentada como metáfora espacial de la modernización neuquina. Las formas que esa expansión asumió, los cambios que la misma imprimió en la estructura urbana y los crecientes problemas que acompañaron su espasmódico crecimiento no fueron examinados en toda su complejidad. Este conjunto de lagunas, atendibles en la medida que se trató de obras de síntesis, complicó enormemente la posibilidad de dar un paso adelante con respecto a esa mirada que tenía a la expansión urbana tan solo como consecuencia necesaria del crecimiento económico provincial y del crecimiento demográfico capitalino.

Llegados a este punto, y en función del estado actual del conocimiento, algunas preguntas se vuelven obligatorias: ¿Cómo operó el proceso de diferenciación socioespacial en la ciudad de Neuquén a lo largo del siglo XX? ¿Cuáles fueron los patrones de segregación que emergieron de las estructuras económicas y demográficas dominantes en cada una de las etapas que transitó la capital provincial en el periodo de nuestro interés? ¿Cómo poner en diálogo la literatura que enfocó su mirada en las áreas metropolitanas con las particularidades de una ciudad intermedia de crecimiento explosivo? 


\section{La segregación urbana desde el tiempo y el espacio. Una aproximación en una ciudad patagónica (Neuquén, 1904-2010)}

\section{El Neuquén Territoriano (1904-1955): distancia social, cercanía espacial y barreras físicas}

Comencemos nuestro recorrido echando una mirada a la Patagonia. Durante los primeros años del siglo XX, apreciamos una débil ocupación del territorio con enormes espacios deshabitados, interrumpidos ocasionalmente por alguna infraestructura humana. Aunque los primeros proyectos de colonización se remontan a los años que siguieron a la mal llamada "conquista del desierto", sus resultados fueron extremadamente pobres. Es lo que Susana Bandieri (2005), con su monumental Historia de la Patagonia, dio en llamar el fracaso colonizador: el afán especulativo, la escasa presencia oficial y la concentración de la tierra no permitieron elevar la densidad demográfica de la franja más austral del territorio argentino. Sus principales actividades económicas, amén de presentar un dispar grado de desarrollo, no fortalecieron el perfil urbano de la región. Antes bien, la fruticultura, la ganadería y la extracción de hidrocarburos le dieron a la Patagonia una apariencia más bien rural: para una fecha tan avanzada como 1947, solo un tercio de su población residía en ciudades o pueblos (Recchini de Lattes, 1973).

Es en ese marco donde debemos domiciliar el caso que nos interesa. Hacia fines del siglo XIX, en las tierras ubicadas en la margen derecha del río Neuquén, justo antes de converger con el río Limay, se conformó un caserío que el común de la población conocía como "La Confluencia". Ese paraje fue ganando importancia con la llegada de diferentes dependencias oficiales. El naciente pueblo era un rancherío disperso en que sobresalían las construcciones de barro y un puñado de comercios. Su importancia en estos primeros años residía en su carácter de escala obligada en la ruta que unía a Carmen de Patagones y Bahía Blanca con los asentamientos militares de los Andes, sobre todo con Chos Malal, capital del joven territorio de Neuquén. No debemos olvidar que, en el cambio de siglo, el grueso de la población se asentaba sobre los Andes, especialmente en el norte, donde una ganadería trashumante, orientada a suplir la demanda de los centros urbanos chilenos, daba vida a una economía mayormente rural. El censo nacional de 1895 es revelador al respecto: dos terceras partes de la población neuquina residía en el cuadrante noroccidental del Territorio (Bandieri y Angelini, 1983).

La llegada del ferrocarril, en 1902, inauguró una nueva etapa en la Confluencia. Con la instalación de la estación, punta de rieles del Ferrocarril del Sud, el número de habitantes de lo que algunos autores denominaron protociudad fue incrementándose hasta llegar al medio millar (AAVV, 2004: 15). En materia económica, el bramido de las locomotoras significó una creciente integración de esta comarca con la pampa húmeda: el duro viaje de carreta desde la Capital Federal, que insumía cuarenta días, se convirtió en una travesía de poco más de un día. Esta cercanía, por lo menos en términos temporales, hizo que la actividad comercial se incrementara y, junto a ella, se comenzara a desarrollar un incipiente sector secundario. En medio del caserío comenzaron a distinguirse algunos establecimientos que abastecían a la población de bienes que estaban naturalmente 
protegidos de la competencia. Sólo para mencionar los rubros más repetidos en las guías comerciales de la época deberíamos señalar algunas herrerías, un horno de ladrillos y una fábrica de gaseosa que funcionaba como anexo de una casa comercial (Silveira, 1988: 30).

En 1904, el gobierno nacional, gracias a la intervención del gobernador Bouquet Roldan, decidió el traslado de la capital desde Chos Malal, al pie de los Andes, hacia el área de la confluencia, quedando fundada así la ciudad de Neuquén. Las razones de esta medida no son difíciles de imaginar: los poseedores de las tierras de lo que luego sería la capital, entre los que contamos al primer mandatario territoriano, tenían una importante capacidad de presión y pensaban que a partir de esa medida sus propiedades se iban a valorizar (Roca, 1981). Esa jugada especulativa fue justificada por una argumentación ajustada a sus tiempos: la nueva capital, ubicada en la intersección de dos ríos y comunicada al resto del país por rutas de hierro, iba a comportarse como una puerta a partir de la cual ingresaría la "civilización". El resultado de este proceso de urbanización, alentado más por el deseo de valorizar los terrenos que de ocuparlos efectivamente, fue un tejido en el que "grupos de casas comenzaron a surgir diseminadas en el vasto plano", mientras que "seguían baldías manzanas enteras que no se ponían en venta o se pedían precios elevadísimos por sus solares" (Edelman, 1954).

La decisión de trasladar la capital al oriente territoriano tuvo un duradero impacto demográfico en la joven ciudad de Neuquén. Gracias a la instalación de las diferentes reparticiones gubernamentales, se produjo un salto en el número de habitantes: el medio millar de 1902 se transformó en dos mil quinientos en 1920, alcanzando los siete mil a mediados del siglo XX (Mases y otros, 1994: 9). Pese este considerable avance, la población neuquina presentaba tasas de crecimiento menores a las del cinturón industrial bonaerense. Apartada de los proyectos industrialistas que habían remodelado la arquitectura demográfica argentina, la ciudad de Neuquén crecía gracias a un incremento vegetativo apenas positivo y a su consolidación como destino de un creciente contingente de migrantes del interior del territorio. Con el deterioro de la ganadería que alimentaba a los mercados trasandinos, sujeta desde los años cuarenta a rigurosos controles fronterizos, el sector oriental del Territorio Nacional comenzó a ganar espacio frente a los departamentos recostados sobre los Andes (Perren, 2012).

El crecimiento de la población dio impulso a una fecunda actividad comercial que incluía, entre otros emprendimientos, galpones de acopio, comercios de ramos generales, tiendas que ofrecían telas provenientes de Buenos Aires, casas de iluminación y puestos de revistas. El sector terciario de la ciudad se completaba con una gama de servicios que iba desde hoteles de cierta envergadura hasta pequeñas peluquerías. Este tipo de actividades, que experimentaron un breve impasse con el traslado de la punta de rieles a Zapala en 1916 (Silveira, 1988: 33-34), fue acompañado de un sector secundario que, sin alcanzar ni remotamente la escala de las ciudades de la Pampa Húmeda, agrupaba emprendimientos dedicados a la producción de bienes de consumo y un puñado de talleres que tenían mucho de 


\section{La segregación urbana desde el tiempo y el espacio. Una aproximación en una ciudad patagónica (Neuquén, 1904-2010)}

artesanal. Si entre los primeros debemos contar la producción de pan, bebidas, jabón y la confección de ropa; entre los segundos no podemos dejar de mencionar algunas carpinterías, talabarterías, talleres de carros, herrerías y fábricas de ladrillos (Gallucci, 2007: 159).

\section{Mapa 1}

Trazado de la ciudad de Neuquén. Etapa territoriana

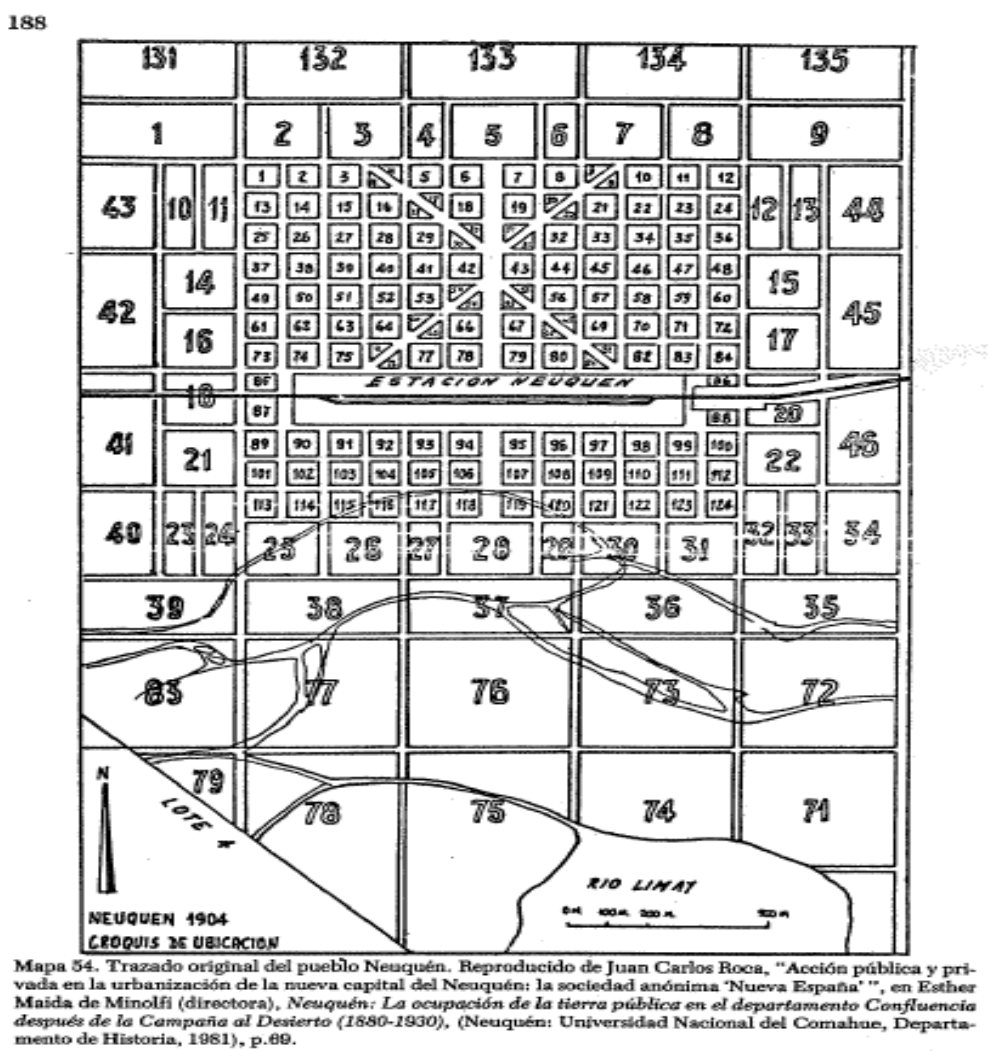

Fuente: Vapñasky, 1983.

Pero no todo en la capital neuquina era intermediación comercial, actividad oficial y un puñado de establecimientos industriales. Las obras de canalización del río Limay hicieron posible un paulatino despliegue del sector primario. Alrededor de la capital del Territorio se establecieron tres colonias agrícolas que conformaban una superficie cultivable de alrededor de mil ochocientas hectáreas (Mases y otros, 1994: 10). En estas chacras, que asumieron la forma de explotaciones familiares, el cultivo de la alfalfa con fines ganaderos y de una horticultura orientada al consumo local fueron la norma en las primera dos décadas del siglo XX. Luego de 1920 apreciamos una franca expansión de una fruticultura cuyos productos comenzaron a comercializarse en los grandes mercados de la Pampa Húmeda. Nuevas iniciativas colonizadoras, como la de los hermanos Plottier y el propio Ferrocarril del Sud, provocaron la triplicación de la superficie bajo riego entre 1920 y 1930. Esta expansión no fue suficiente para que Neuquén perdiera su "carácter absorbentemente administrativo" (Varpnarsky, 1983: 191), a muchos cuerpos de distancia de la capital productiva de la Patagonia norte: General Roca, en el vecino Territorio Nacional de Rio Negro. 
La distribución espacial de estas economías se superponía con el mapa social de la ciudad de Neuquén. Como en las ciudades preindustriales europeas, tan bien retratadas por Sjoberg (1960), la cercanía con respecto al lugar de trabajo era un principio ordenador del espacio urbano. No es casual que esa población compuesta de "comerciantes, empleados y jornaleros de diversos oficios y gente de buen pasar" (AAVV, 2004: 59) se haya distribuido de forma desigual en el territorio. En términos generales, y apelando a la amplia literatura sobre el tema (Silveira, 1988, Mases y Montes Le Fort, 2001; y AAVV, 2004), distinguimos un esquema tripartito que surcó con éxito la primera mitad del siglo XX: un "Alto" rico, un "Bajo" popular y, entre ambos, un aislado, donde se desarrollaban las actividades ferroviarias y residía el personal dedicado a esas labores (Mapa 1). Es interesante cómo el relieve de la ciudad, ubicada en borde de un valle fluvial, con una parte elevada y otra deprimida, reflejaba en buena medida la estructura de clases. Esta realidad de segregación era acentuada por la existencia de barreras físicas que reforzaban las distancias sociales. Hasta la década de 1930, cualquier flujo en sentido sur-norte o norte-sur debía franquear una tranquera controlada por el personal de Ferrocarriles del Sud. La descripción que Vapnasky hiciera de la morfología del "Neuquén Territoriano", aunque elaborada hacia comienzos de los ochenta, no ha perdido validez:

\begin{abstract}
"Neuquén adquirió una fisonomía que sólo durante los últimos diez años se comenzó a desdibujar: la zona norte se tornó un barrio exclusivamente residencial y administrativo, y allí se fueron construyendo todos los edificios públicos; al sur de la playa ferroviaria más vasta de toda la línea entre Bahía Blanca y Zapala, se formó el barrio comercial" (1983: 179)
\end{abstract}

La persistencia de esta configuración no debería ocultar un elemento a todas luces novedoso: una nueva ciudad se estaba construyendo detrás de los bordes de la ciudad tradicional. Este nuevo espacio se encontraba, en gran medida, desconectado de la grilla trazada al momento de la fundación. Con calles laberínticas y la falta de los más básicos servicios públicos, se comportaba como una zona de frontera al interior de una ciudad que complejizaba su estructura. En parte resultado del fraccionamiento de chacras no demasiado productivas y en parte de la ocupación de terrenos fiscales, los vecindarios más retirados funcionaban, al decir de Gorelik (2004: 259), como avanzadas domésticas de un campamento provisorio. Los testimonios de la época no dejan lugar a dudas. En las cercanías del matadero, en el sureste del trazado urbano, nos topamos con "cuadros para tener ganado, con pasto y arroyitos (a su disposición)"4. Era habitual que allí la hacienda ingresada a la comuna hiciera su último engorde antes de la faena. Los servicios en esa zona se reducían a una canilla comunitaria y a la electricidad que proveía la Cooperativa de Agua, Luz y Fuerza. La falta de gas, por su parte, era compensada con leña extraída de los bosques que seguían el curso del río Limay y los desagües a cielo abierto

\footnotetext{
${ }^{4}$ Archivo Histórico de la Provincia de Neuquén (en adelante AHPN), Caja Barrios, Belgrano. La memoria de su gente, Neuquén, 1989, p. 9.
} 


\section{La segregación urbana desde el tiempo y el espacio. Una aproximación en una ciudad patagónica (Neuquén, 1904-2010)}

volvían el aire irrespirable 5 . Los campamentos de gitanos, con sus carpas comunitarias y actividades marginales, además de preocupar a las autoridades ${ }^{6}$, alternaban con viviendas rudimentarias en un paisaje típicamente suburbano. Esta descripción, aunque refleja la realidad del barrio Belgrano, sirve para perfilar otras áreas que se desarrollaron en las décadas de 1940 y 1950 (Villa Farrell, Mariano Moreno, Villa María, Villa Florencia y La Sirena).

Recapitulemos. El examen de la evidencia reunida nos permite caracterizar al "Neuquén territoriano" como una ciudad claramente segregada. La condición social, quizás como ninguna otra variable, permitía entender la disposición de la población en el tablero urbano. No apreciamos grandes distancias físicas que separaran pobres de ricos, pero sí dispositivos, como las tranqueras, que complejizaban la circulación al interior de la capital neuquina. Las consecuencias de este hecho no son menores para el análisis de la diferenciación socioespacial: en las primeras décadas del siglo $\mathrm{XX}$, el fenómeno de la segregación no solo operó sobre los stocks, sino también sobre los flujos. Al mismo tiempo, es preciso señalar un segundo elemento: la ciudad cargó desde su propio nacimiento con una baja densidad y un crecimiento claramente centrífugo. El papel jugado por el capital inmobiliario, especialmente por la Sociedad Nueva España, nos ayuda a explicar ambos rasgos. Su deseo de valorizar nuevas áreas de la ciudad hizo que los loteos fueran discontinuos y que, solo cuando llegaran los servicios básicos, se comercializaran los espacios reservados. Esto fue así al punto que el propio Vapnasky señalaba que Neuquén era "el caso más notorio en todo el norte de la Patagonia de dispersión y expansión innecesaria e inadecuada del tejido urbano" (1983:189).

\section{El Neuquén desarrollista (1955-1991): distancia social, lejanía espacial y polarización}

El "desarrollismo" dio aire fresco a los periféricos distritos del sur argentino. El intento de desmontar el modelo agroexportador y de erigir en su lugar una maquinaria industrial diversificada, impulsó la búsqueda de fuentes energéticas acordes con esta nueva meta. Una economía que, hasta allí, había mirado "hacia fuera" mostró un creciente interés por crear "polos de crecimiento", que irradiarían su influencia al conjunto nacional. Esta nueva sintonía ideológica, que valorizaba el papel planificador del Estado, tuvo a la provincia de Neuquén como un escenario privilegiado. En ese contexto, la construcción de grandes represas para la producción de energía, articulada con la expansión en la explotación de hidrocarburos, benefició especialmente a la capital neuquina. Esto gracias a que diferentes autoridades provinciales propiciaron la radicación en la ciudad de aquellas empresas a cargo del usufructo de esos recursos, pero también porque la prestación de servicios a las mismas se concentró en su planta urbana. De esta

\footnotetext{
${ }^{5}$ AHPN, Caja Barrios, Belgrano. La memoria de su gente, Neuquén, 1989, p. 21.

${ }^{6}$ Archivo Histórico de la Municipalidad de Neuquén (en adelante AHMN), Gestión de Gobierno, Caja 1 , nota 384 .
} 
forma, la edificación de una matriz estado-céntrica y la demanda de brazos que ella trajo aparejada fueron de vital importancia en la atracción de contingentes migratorios de diferentes procedencias, que constituyeron el nuevo motor de su desarrollo demográfico.

En unos pocos años, esa pequeña localidad se transformó en una de las urbes de mayor crecimiento durante la segunda mitad del siglo XX. Entre 1960 y 1991, la población de la ciudad transitó de los veinticinco mil habitantes a una cifra próxima a los doscientos mil. Las tradicionales corrientes migratorias, originarias del interior neuquino y de Chile, comenzaron a convivir con un nuevo flujo que provenía de diferentes regiones argentinas como el conurbano bonaerense, Córdoba, Rosario y Mendoza. Bajo el efecto de una demanda laboral que avanzaba a un ritmo hasta entonces desconocido, Neuquén se consolidó como una área receptora y, como no podía ser de otra forma, su estructura demográfica experimentó un radical cambio: una población persistentemente joven y el creciente peso de los migrantes marcaron los ritmos de una ciudad que abandonaba su perfil parroquiano para convertirse en un centro de servicios, que atendía a un área urbana dispersalocalizada en las márgenes de los ríos Neuquén, Limay y Negro.

La creciente importancia económica y demográfica modeló los límites de una ciudad que avanzaba rauda hacia una estructura polarizada. Una forma de dar cuenta de este proceso es aplicando el Índice de disimilitud (ID). Esta herramienta nos avisa sobre cuán semejante es la distribución de dos subpoblaciones en las unidades espaciales en las que se divide la ciudad (Massey y Denton, 1988): un valor cercano a 100 nos indicaría que el grupo en cuestión no comparte las áreas residenciales con miembros del otro grupo (realidad de segregación); uno próximo a cero nos muestra que la proporción de ambos grupos para cada una de las áreas estudiadas es idéntica (realidad de integración). Tomando la ocupación declarada a la hora de contraer nupcias, calculamos, para la década de 1960, el ID entre quienes se alojaban en los extremos de la clasificación profesional: por un lado, trabajadores "no manuales altos" y "profesionales bajos" y "altos"; mientras que, por el otro, a quienes se desempeñaban en trabajos manuales semicalificados y en otros que no requerían conocimientos específicos (Perren, 2011). Un ID próximo a 80 revela la escasa mezcla habitacional entre ricos y pobres. La segregación, ese fenómeno que acompaña a Neuquén desde su propio nacimiento, no hizo más que reforzarse en las décadas centrales del siglo XX, tal como han demostrado numerosas investigaciones (Perren, 2009, 2010 y 2011). 


\section{La segregación urbana desde el tiempo y el espacio. Una aproximación en una ciudad patagónica (Neuquén, 1904-2010)}

Mapa 2

El temprano Neuquén desarrollista (década de 1960)

Distribución espacial de los estratos inferiores

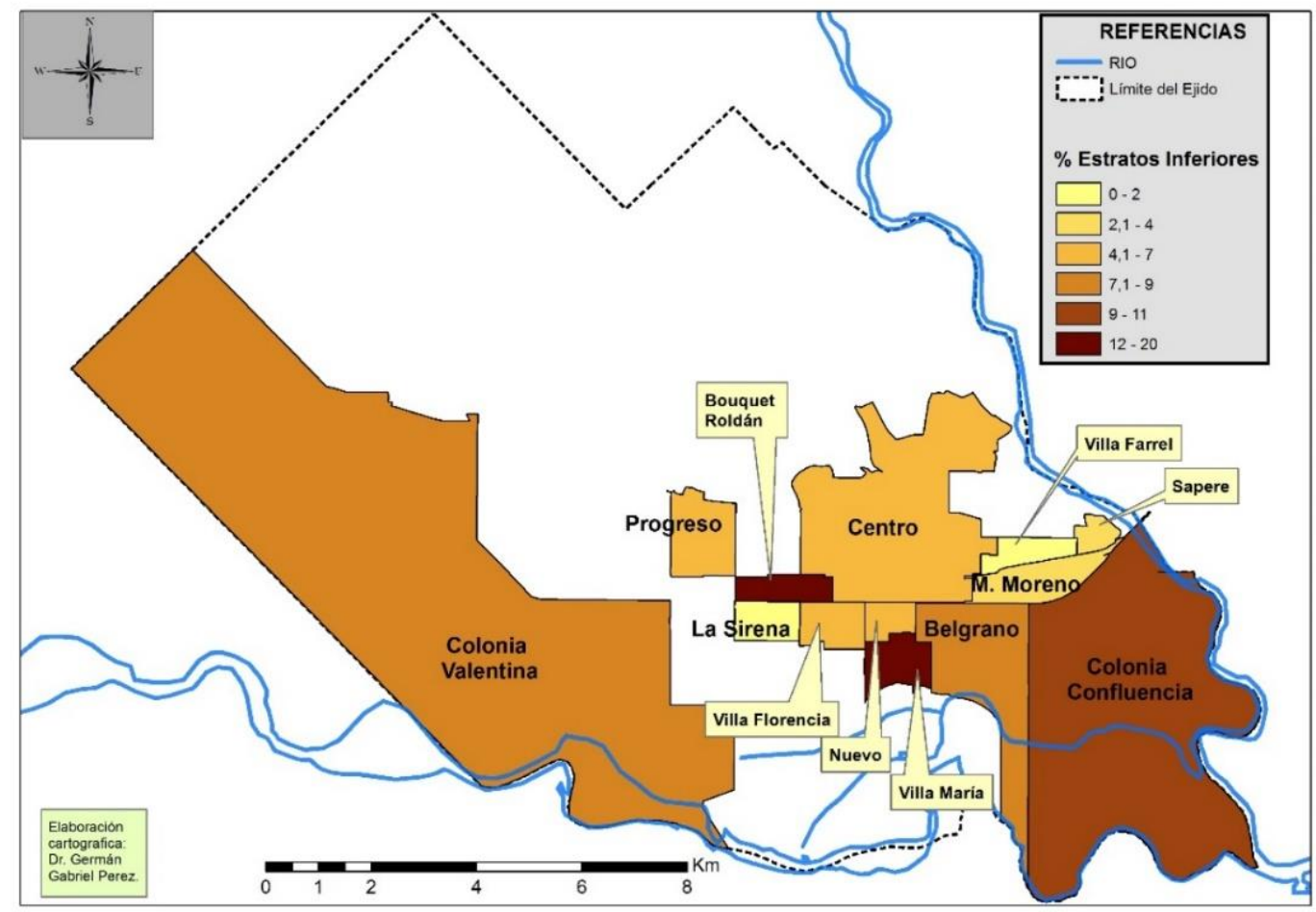

Fuente: Elaboración propia

Cuando volcamos en el mapa la información ocupacional no sólo advertimos una significativa segregación, sino también un esquema análogo al modelo de zonas concéntricas de Burgess (1924), aunque en una dirección exactamente opuesta. La propuesta de la escuela de Chicago se esforzaba en demostrar que el nivel social de los habitantes aumentaba conforme nos alejamos del centro de la ciudad. En Neuquén, hacia mediados del siglo XX, ese nivel disminuye a medida que realizamos el mismo movimiento (Mapas 2 y 3). Alejada de la innercity norteamericana, esa área dilecta de la mala vida y donde abundaban los migrantes de primera generación, el área central neuquina albergaba los porcentajes más altos de personas empleadas en los peldaños superiores de la estructura ocupacional y, al mismo tiempo, una proporción bastante menor de trabajadores semicalificados o sin calificación. El damero original pasaba por un momento de transición. Es verdad que algunos rubros todavía estaban alineados con el pasado territoriano. Entre los más visibles podemos señalar su aspecto abandonado, la falta de higiene o un Estado municipal mínimo fueron quizás los elementos más visibles. Otros, sin embargo, estaban sintonizados en una frecuencia completamente diferente. Aunque la infraestructura urbana estaba a la zaga de la de otras ciudades de mayor tradición, no menos evidentes fueron las novedades que la surcaron: la ciudad perdió su carácter de frontera, esa eterna provisionalidad, para desandar un sendero de complejización edilicia y, por supuesto, social. 
Rodeando el centro se levantaba una franja, al este y al sur del centro, que involucraba una menor proporción de integrantes de los estratos superiores. Un informe realizado sobre finales de la década de los setenta ponía a esta zona en un lugar de privilegio. Con comisiones vecinales funcionando desde muy temprano, contaban -en mayor o menor medida- con los principales servicios públicos. Si bien no encontramos allí desagües cloacales, sistemas de alumbrado potentes o calles asfaltadas, conformaban un cinturón de barrios que no estaban sumergidos en una situación crítica. En esa columna encontramos áreas de antiguo poblamiento que sólo algunas décadas antes estaban totalmente desconectadas del tejido urbano neuquino. En los barrios Mariano Moreno, Villa Florencia, Villa Farrell, Nuevo y Belgrano nos topamos con "casas de material con agua y luz" que albergaban a una población formada por "obreros y empleados de empresas estatales, privadas y comercio"?.

\section{Mapa 3 \\ El temprano Neuquén desarrollista (década de 1960) Distribución espacial de los estratos superiores}

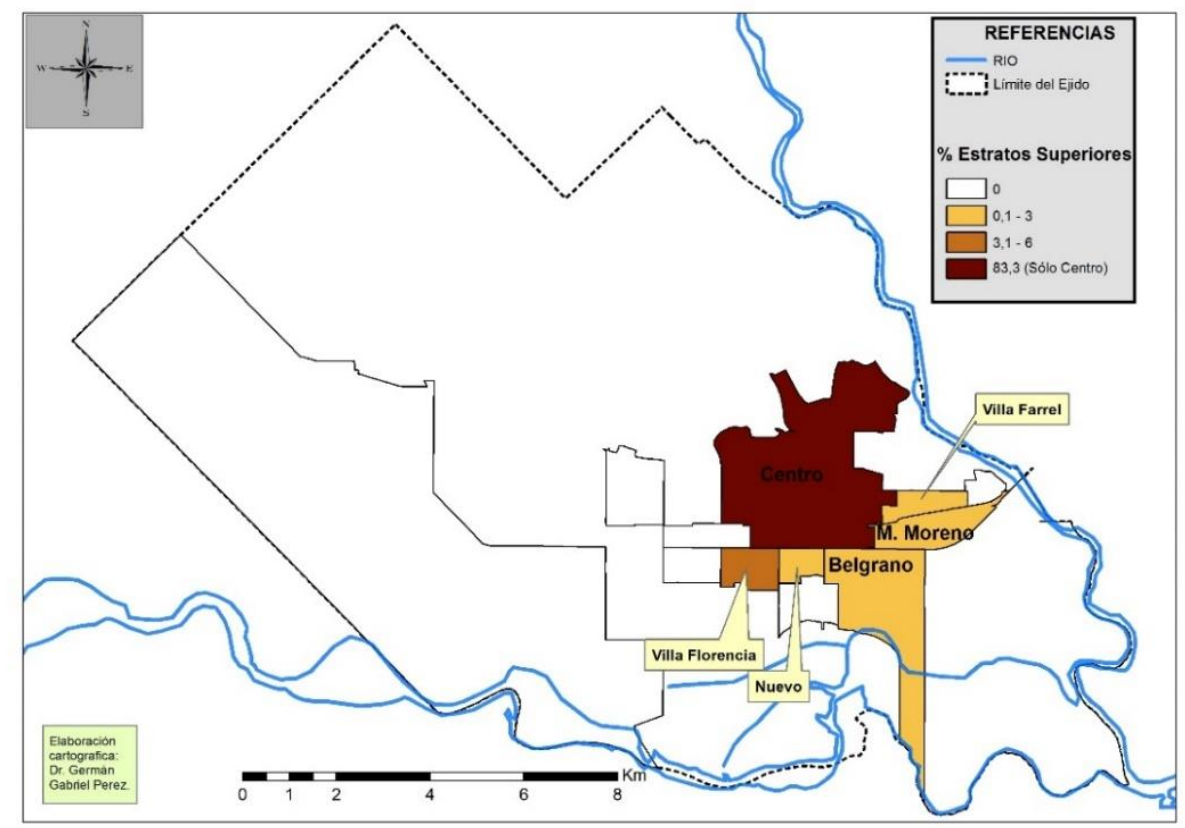

Fuente: Elaboración propia.

Los barrios nacidos a mediados del siglo XX constituían, sin duda, una segunda franja de la estructura urbana neuquina. Observamos en ellos una ausencia total de personas empleadas en el vértice superior de la pirámide profesional y una significativa participación de los trabajadores menos calificados. Estas zonas se habían ganado el mote de "villas" o "cordón de emergencia"8 debido al retraso que evidenciaban en materia de servicios. A bastante distancia de los barrios más antiguos, estos sectores presentaban viviendas muy precarias construidas con materiales como abobe, chapas, cantoneras y, en casos extremos, hasta cartón. Esta

\footnotetext{
${ }^{7}$ AHPN, Neuquén, 75 años de capitalidad, 1979, p. 127.
}

${ }^{8}$ AHPN, Neuquén, 75 años de capitalidad, 1979, p. 127. 


\section{La segregación urbana desde el tiempo y el espacio. Una aproximación en una ciudad patagónica (Neuquén, 1904-2010)}

descripción, aunque panorámica, funcionaba para retratar a las áreas conocidas como Bouquet Roldan, Villa María, La Sirena, Sapere y lo que luego se denominaría Progreso. A todas ellas debemos sumar los vecindarios que sobrevivían en los márgenes de las colonias agrícolas Confluencia y Valentina, donde sus habitantes alternaban el 'trabajo para otros' con prácticas de subsistencia.

Poco de este panorama de segregación había cambiado en las siguientes dos décadas. Ante todo, la distancia entre sectores acomodados y populares seguía siendo importante. Para sostener este punto basta con decir que el ID se mantuvo a un nivel muy elevado (cercano a 75). Notamos también la permanencia de ese esquema de zonas concéntricas que invertía la lógica sugerida por Burgess: al igual que los sesenta, el nivel social de los habitantes disminuía a medida que realizamos un movimiento "hacia fuera". Aquellos criterios que utilizamos para comprender su distribución de la población tampoco perdieron actualidad: la proximidad al centro era el mejor indicador para medir la calidad del empleo y las ventajas de la zona. Los profesionales y quienes se desempeñaban en empleos no manuales altos alcanzaban su pico en los distritos centrales, disminuían sensiblemente en un primer anillo y alcanzaban su mínimo en los asentamientos que se abrían paso en la periferia neuquina. En la vereda opuesta encontramos a las ocupaciones manuales de menor calificación: su escasa participación en el centro de la ciudad era compensada por una abundancia en los espacios de más reciente urbanización.

Mapa 4

El tardío Neuquén desarrollista (décadas de 1970 y 1980)

Distribución espacial de los estratos inferiores

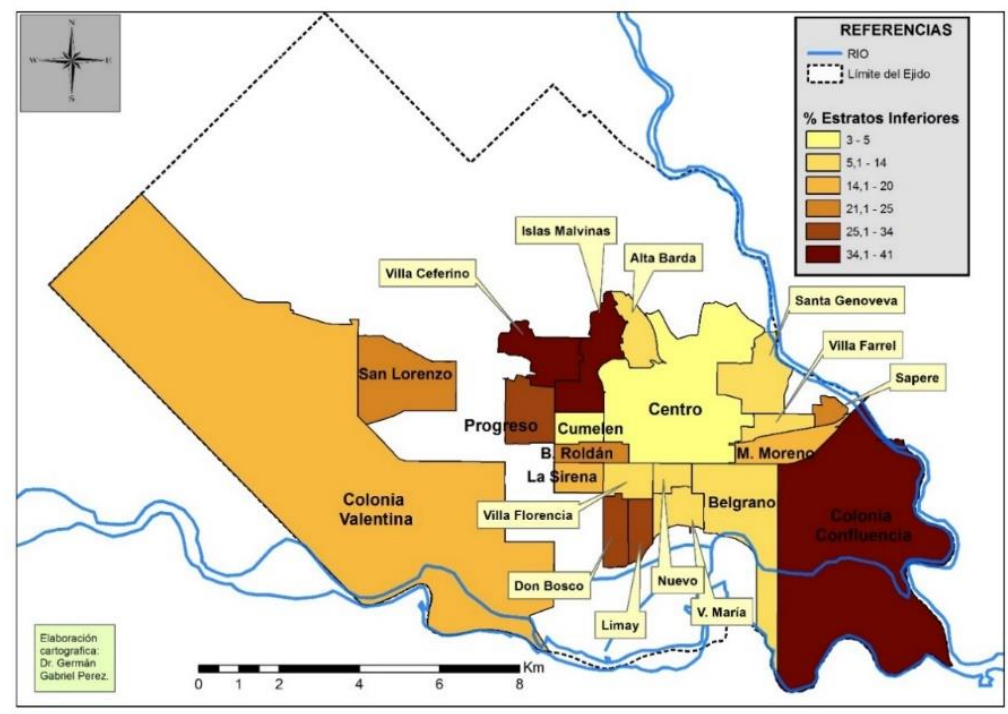

Fuente: Elaboración propia

La continuidad de este criterio no debería confundirse con una estructura urbana inmutable. Por el contrario, el periodo 1970-1991 exhibió interesantes variantes que nos obligan a enriquecer el modelo de un centro y dos franjas contiguas (Mapa 4 y 5). En principio, no podemos dejar de señalar la exportación del perfil ocupacional del centro a otros espacios. La dinámica del mercado inmobiliario nos ofrece algunas pistas al respecto. Aunque las publicidades de la época ofrecían 
lujosos departamentos en el corazón de la zona bancaria, la abundancia de tierras en las cercanías del casco histórico facilitó la expansión de la ciudad en un sentido horizontal, reforzando una expansión en un sentido horizontal. Los generosos planes de pago, una infraestructura extendida y su cercanía respecto al centro sirvieron de base a una apresurada ocupación de áreas del antiguo primer anillo, así como también de espacios que hasta entonces eran sólo descampados. Este fenómeno nos permite comprender el creciente peso de sectores como Villa Farrell, Alta Barda,Cumelén o Santa Genoveva.

\section{Mapa 5}

El tardío Neuquén desarrollista (décadas de 1970 y 1980)

Distribución espacial de los estratos superior

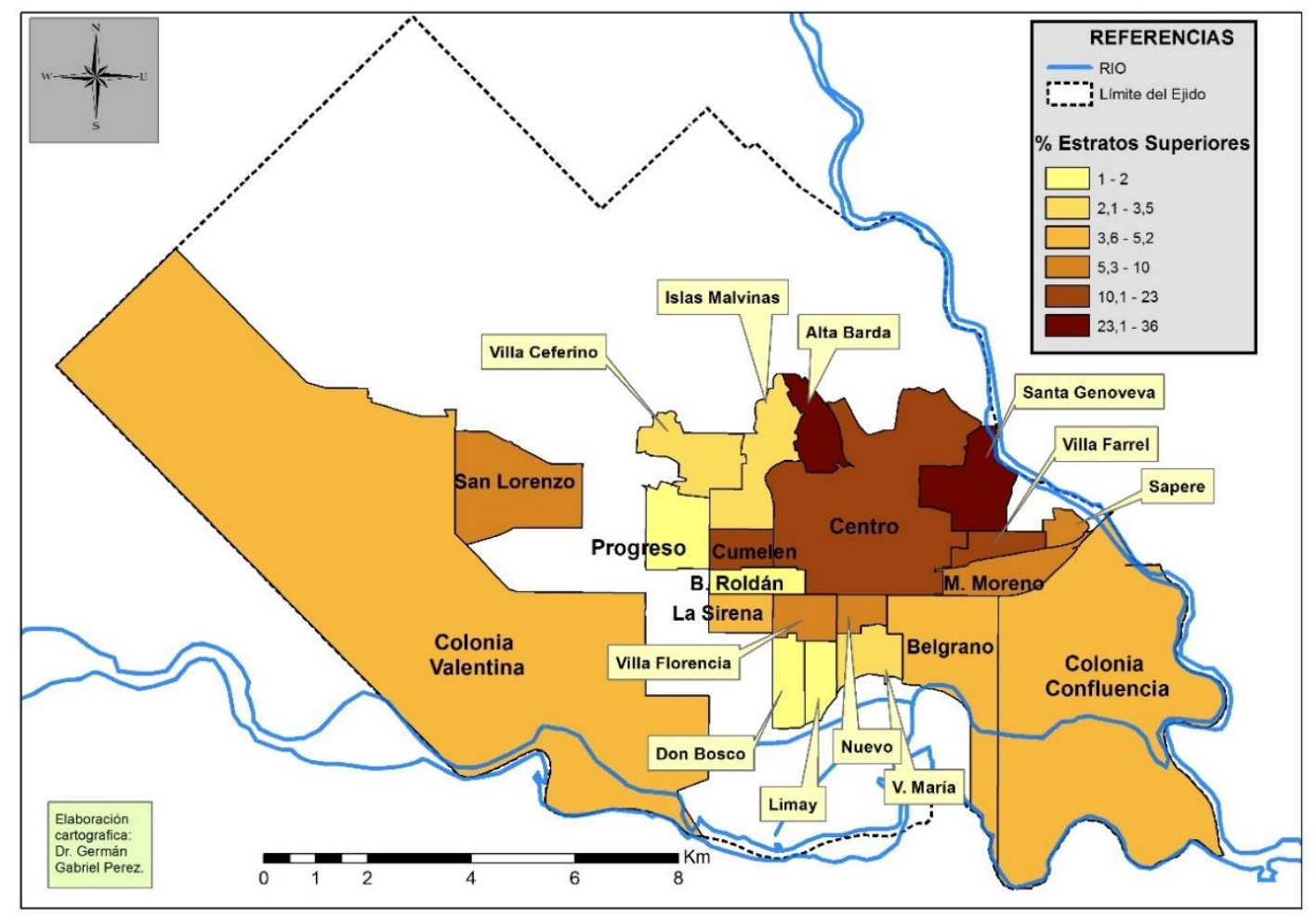

Fuente: Elaboración propia

A continuación de esta suerte de "centro extendido", observamos barrios que presentaban una menor cantidad de profesionales y una mayor proporción de trabajadores manuales. En este rango encontramos algunos de los distritos más antiguos de la ciudad, totalmente consolidados desde el punto de vista urbanístico, pero también otros que aparecían en los sesenta como asentamientos precarios. En la intersección entre las demandas más articuladas de los vecinos y un Estado dispuesto en invertir en infraestructura, encontramos un proceso que terminó borrando el límite entre los barrios y vecindarios que antes formaban el primer y el segundo anillo de la ecología urbana neuquina. Mientras los espacios más antiguos prosiguieron su lenta integración al tejido de la ciudad, aquellos más rezagados fueron objeto de un acelerado proceso de mejoramiento que suavizó esa imagen de "campamento provisorio". 


\section{La segregación urbana desde el tiempo y el espacio. Una aproximación en una ciudad patagónica (Neuquén, 1904-2010)}

Con una insignificante participación de quienes se empleaban en el vértice superior de la pirámide profesional, los vecindarios nacidos a mediados de los setenta se comportaban como el segundo anillo de la arquitectura urbana neuquina. Esta "nueva periferia", que constituía un verdadero desierto en materia de servicios públicos, experimentó en los ochenta un crecimiento extraordinario. A mediados de los ochenta eran más de dos mil las familias que habitaban en los asentamientos precarios que se abrían paso en la periferia neuquina, desde el extremo oriente ("La Costa") hasta en el confín occidental del ejido municipal (Colonia Valentina Sur) ${ }^{9}$. Los quince "asentamientos irregulares de viviendas precarias" sumaban doce mil habitantes, cerca de la mitad de los cuales no habían cumplido aún los doce años. Quienes habitaban en estos espacios de relegación representaban un décimo de la población. Una comparación puede que nos ayudea entender su importancia. Para el período que nos ocupa, distritos que la literatura académica suele asociar a este particular tipo de enclave de la pobreza -como Lanús, en el conurbano bonaerensemostraban una proporción similar de habitantes residiendo en "villas miseria" (Auyero y Hobert, 2005: 233).

Una última novedad nos conduce a un elemento que hace a la esencia del periodo: los complejos oficiales. Frente a un severo desajuste entre oferta y demanda habitacional, no es extraño que el peso de la construcción de viviendas haya recaído sobre las espaldas del Estado provincial a través de una agencia fundada para tal fin: el Instituto Provincial de Vivienda y Urbanismo de Neuquén (IPVUN). El incremento de los recursos llegados por la liquidación de regalías hidrocarburíferas, sumados a los aportes extraordinarios del tesoro nacional, permitieron llevar adelante una activa política en materia de viviendas: cerca de ocho mil unidades habitacionales fueron construidas en la capital neuquina y sus alrededores. De todos modos, entre los numerosos complejos habitacionales inaugurados quedaron atrapadas amplias franjas de tierra desocupada: la erección de estas auténticas "islas de la periferia", impulsadas por la necesidad de edificar planes de vivienda oficiales al menor costo posible, complicaron enormemente la provisión de los servicios elementales, al tiempo de reforzar un cuadro de relativo aislamiento espacial.

Antes de avanzar sobre la última etapa, hagamos una breve síntesis de lo hasta aquí trabajado. No estaría mal si dijéramos que, en las décadas centrales del siglo XX, se reforzaron las tendencias que visualizamos en el "Neuquén territoriano". En primer lugar, advertimos una realidad de fuerte segregación, aunque con notorias diferencias con respecto a la etapa anterior. La cercanía espacial entre ricos y pobres se volvió un lejano recuerdo del pasado. Su lugar fue ocupado por un patrón claramente polarizado, con áreas centrales habitadas por las elites y los sectores populares abriéndose paso en dirección a la periferia. La distancia social comenzó a implicar una mayor distancia física. Esa "segregación a gran escala" fue resultado de un proceso que podría leerse en términos de continuidad: el "Neuquén Desarrollista" dio curso a una urbanización dispersa, escasamente compacta o,

\footnotetext{
${ }^{9}$ La Revista de CALF, “Informe especial: Villas emergencias”, $\mathrm{n}^{\circ}$ 86, año 8, pp. 4-5.
} 


\section{Joaquín Perrén - Germán Pérez}

usando términos técnicos, de tipo fuzzy. Mucha importancia tuvo en este fenómeno el real estate que, en su búsqueda insaciable por rentas, dosificó la incorporación de lotes al mercado inmobiliario, esperando que los mismos se valoricen con la llegada con equipamiento urbano. Pero no podemos dejar de mencionar, y aquí radica un elemento novedoso, un segundo actor productor de ciudad: el estado provincial. Su intervención hizo que la explosión de la superficie edificada conviviera con enormes espacios desconectados del tejido urbano, colaborando de manera decisiva en el crecimiento extensivo de la ciudad.

\section{El Neuquén Neoliberal (1991-2010): distancia social, cercanía espacial y fragmentación}

A partir de los años noventa, la provincia de Neuquén experimentó una transición desde una economía desarrollada bajo un modelo de capitalismo de estado, en el que la explotación de los recursos naturales estuvo en manos de empresas públicas, hacia un modelo al que podríamos ubicar en el cuadrante del neoliberalismo. Resultado de este proceso, condicionado en gran medida por la reorientación de carácter privatista y desregulatorio del estado nacional, la economía neuquina profundizó su dependencia en relación con la extracción de hidrocarburos. Como bien señalaron Domeett, Kopprio y Landriscini, fue recién "a fines de la década del 80 e inicios del 90 cuando comienza a estructurarse la economía primariodependiente tal como se la conoce en la actualidad, signada por la finalización de las grandes obras hidroeléctricas y la mayor producción hidrocarburífera ocasionada por la desregulación del sector en los años 1991/1993" (2008).

La revisión de algunos indicadores básicos de desempeño es suficiente para confirmar el "giro extractivista" que experimentó la economía neuquina hacia comienzos de los noventa. Por aquellos años, la explotación de petróleo y gas se convirtió en el rubro que mayor aportación hizo a la formación del Producto Bruto Geográfico (PBG): entre los años 1993 y 2006, la participación de aquel sector en el total perforó la barrera del 50\%, duplicando el promedio de la década anterior y alcanzando su máximo histórico en 1998 (una proporción cercana al 70\%). Este vuelco, que permitió incrementar el aporte de la cuenca neuquina en el conjunto nacional, reforzó esa imagen que tenía a Neuquén como una provincia petrolera, una especie de emirato enclavado en el corazón de la Patagonia. Esta brusca aceleración del crecimiento no debería hacernos perder de vista dos elementos que no hicieron más que intensificarse en las siguientes dos décadas: si, por un lado, la economía neuquina fue objeto de un severo proceso de concentración; por el otro, notamos el reforzamiento de una lógica "insular" de funcionamiento.

El proceso acelerado de urbanización iniciado en la etapa anterior se potenció por estos nuevos niveles de actividad. Esa ciudad que, en 1991, no alcanzaba los 170 mil habitantes pasó a tener 231 mil ya en 2010. En veinte años, la capital provincial sumó más de 60 mil nuevos pobladores. En términos espaciales este crecimiento derivó en una expansión caótica y no planificada de la planta urbana principalmente 


\section{La segregación urbana desde el tiempo y el espacio. Una aproximación en una ciudad patagónica (Neuquén, 1904-2010)}

hacia la zona noroeste del ejido municipal y en sectores fiscales que no pudieron ser resguardados por el estado municipal. Esta expansión demográfica dio curso a un proceso de metropolización que no respetó los límites de los ejidos municipales cercanos. Se evidencia en la actualidad un proceso de conurbación avanzado que integraría a las áreas urbanas de Cipolletti, Centenario, Plottier, Fernandez Oro, Las Perlas y Cinco Saltos (Pérez, 2018).

El "Neuquén neoliberal" fue un escenario en el que la segregación resultó un ingrediente fundamental. Podemos aproximarnos a esta desigual distribución de los grupos sociales en el territorio a través del ID, aunque introduciendo algunas variantes con respecto a lo realizado en la sección anterior. En lugar de utilizar a los barrios como unidades de análisis, trabajaremos con información a escala de radio censal, máximo nivel de desagregación ofrecido por los censos nacionales de 1991, 2001 y 2010. Al mismo tiempo, abandonaremos la ocupación declarada a la hora de contraer nupcias y usaremos una variable que presenta una mayor cobertura y confiabilidad: el Máximo Nivel de Instrucción (MNI). Puntualmente, prestaremos atención a dos subpoblaciones: una que abarca a quienes no habían culminado sus estudios primarios (MNI Bajo); mientras que la otra involucra a quienes ostentaban un título universitario (MNI Alto). Los datos obtenidos nos muestran la alta correspondencia que existe entre la distribución espacial de los grupos y las distancias socioeconómicas entre ellos. En los veinte años estudiados, cerca de dos terceras partes de los miembros del grupo de MNI bajo debían cambiar su lugar de residencia para obtener una igual distribución respecto del grupo de MNI alto en todas las áreas de la ciudad. Esta continuidad nos avisa sobre una tendencia de largo aliento que pareciera entender poco de coyunturas económicas favorables o desfavorables.

La estructura socioespacial del "Neuquén neoliberal" es a todas luces más compleja que la presentada en las etapas anteriores. Basta con echar un vistazo a la distribución de la población con MNI alto para sostener esta idea (Mapa 6). Al igual que en la fase "desarrollista", la centralidad es un primer elemento que ordena el paisaje urbano. El damero original de la ciudad, por su accesibilidad y mejor dotación de servicios, siguió albergando a los miembros más encumbrados de la sociedad, aunque fue objeto de un proceso de elitización que lo volvió mucho más homogéneo que en el pasado (Perren, Pérez y Cabezas, 2018). En segundo término, advertimos una disposición en forma concéntrica. Tal como desliza la geografía alemana y la norteamericana, visualizamos una suerte de degradee que va perdiendo brillo conforme avanzamos en dirección a la periferia (Ford, 1996; Mertins, 2003 y Bordorf; 2003). En ese tránsito advertimos una extensa área, coincidente con el sur y el "cercano" oeste de la ciudad, que disponía de servicios como desagües, pavimento e iluminación. En caso de usar el modelo de Griffin y Ford (1996) no dudaríamos en pensarla como "zonas madurez". Los dos primeros anillos que distinguimos en la temprana etapa provincial fundieron sus límites y se convirtieron en un espacio compacto que presentaba un alto grado de consolidación. 
Esta configuración concéntrica convivía con dos elementos sectoriales. Por un lado, notamos una expansión de las pautas residenciales de las clases más favorecidas que se extiende de forma lineal, siguiendo las direcciones de tres vías de comunicación fundamentales (la calle San Martín hacia el oeste, la avenida Olascoaga hacia el sur y la ruta provincial $\mathrm{n} \mathbf{0} 7$ hacia el norte). En cada una de estas cuñas distinguimos con claridad aquello que Ford (2003) llamó spine, una estrecha área en la que sobresalía la actividad comercial y alrededor de la cual quedaba delimitado un sector residencial de elite que se desplegaba en sentido a la periferia. Por el otro, debemos señalar un área que se extendía, en forma de abanico, hacia los márgenes, en la que convivían diferentes configuraciones habitacionales, desde viviendas edificadas por sus propios moradores hasta proyectos oficiales de construcción. En esta área de "acrecentamiento in situ" (Ford, 1996), resultado de la acelerada expansión de la ciudad en las décadas de 1980 y 1990, no se observan carencias materiales significativas, aunque sí comenzaba a insinuarse un fenómeno de cohabitación.

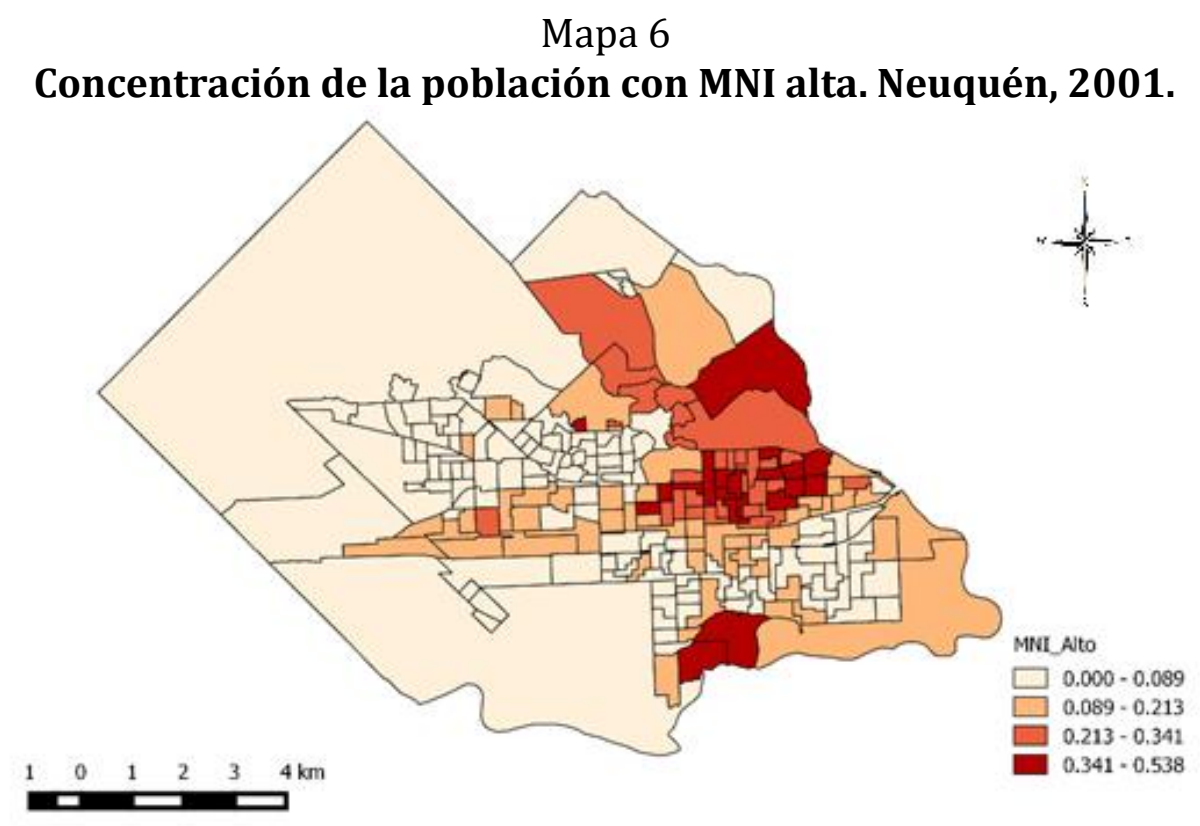

Fuente: Elaboración propia

Por último, no podemos dejar de notar estructuras celulares que redondean los límites de una morfología a todas luces compleja. Al igual que en el "Neuquén desarrollista", las unidades espaciales que presentaban una mayor vulnerabilidad social poseían una disposición en forma de enclaves, solo que, con el desembarco de las recetas neoliberales, no hicieron más que aumentar en número y en dimensión. En 1984, la capital provincia albergaba un total de 17 "asentamientos ilegales" que reunían una población aproximada de doce mil habitantes. Veintinueve años más tarde eran 45 las "villas de emergencia", algunas regularizadas y otras en una situación de incertidumbre, en las cuales residían más de veinte mil personas (TECHO, 2013: 15). En estos espacios de relegación asistimos simultáneamente a 


\section{La segregación urbana desde el tiempo y el espacio. Una aproximación en una ciudad patagónica (Neuquén, 1904-2010)}

"una negación de infraestructura adecuada y la rutinaria ausencia de protección contra los riesgos y peligros ambientales", usando las palabras que usaron Auyero y Burbano para explorar el caso del Gran Buenos Aires (2012: 14). Este cambio de escala que tuvo la segregación en el Neuquén neoliberal no hizo más que incrementar su "malignidad", pues "cuanto mayor es el tamaño de las áreas homogéneas en pobreza, los problemas urbanos y sociales para sus residentes se agravan" (Sabatini, 2003: 7).

Pero estos procesos de encapsulamiento no solo se dieron "por debajo". En los años que comprende el "Neuquén neoliberal" notamos un proceso de periferizaciónde las pautas residenciales de la elite. Este fenómeno privilegió áreas que poseían un indiscutido atractivo paisajístico, ya sea debido a su cercanía a la zona ribereña o bien por presentarse como una suerte de oasis verde en el corazón de un área dedicada a la fruticultura. Lo que en los noventa se resumía a dos countries, se volvió una miríada de urbanizaciones cerradas localizadas mayormente en antiguas áreas rurales. El incremento del valor del suelo de los lotes céntricos, sumado al interés del estado municipal y de los desarrolladores de sumar nuevas zonas a la marea urbanizadora, hizo que numerosos propietarios se desprendieran de sus chacras, provocando una profunda transformación en un paisaje que, desde comienzos del siglo XX, había sido rural. Fue así como "una zona ribereña que históricamente era considerada marginal, inundable, con presencia de reservorios de vivienda social o asentamientos precarios (...) comenzó a disputarse como territorio para las urbanizaciones de privilegio" (Romero y Goycochea, 2016).

Resumamos. El Neuquén neoliberal exhibe un conjunto de permanencias y cambios en relación con las etapas anteriores. Entre las primeras debemos mencionar una segregación residencial que pareciera cruzar de manera oblicua el siglo XX. Pero, debajo de este mar de continuidades, se ocultaba una transformación decisiva: en los noventa se produjo la génesis de un proceso de fragmentación (Janoschka, 2002 y Portes y Roberts, 2005). Tomando distancia de esa realidad dual tan cara al desarrollismo, la ciudad tendió a funcionar como una sumatoria de islas dispersas, permitiendo aquello que, hasta allí, había sido imposible: la lejanía social comenzó a ser compatible con la cercanía espacial (Cuenya, 2018: 2). Sin anular el clivaje entre centro y periferia, los extremos de la estructura social habitaban en áreas extremadamente homogéneas, muy próximas entre sí, aunque con nula interacción. Esto último era posible gracias a la proliferación de dispositivos de separación: no se trataba de las tranqueras de la empresa ferroviaria, aquellas que había dificultado la circulación en la fase territoriana, sino de alambrados, puestos de vigilancia, cámaras y barreras. En pocas palabras, la "segregación a gran escala" fue reemplazada por una microsegregación (Sabatini, 2003).

Una segunda continuidad con cambios es aquella que se refiere al proceso de urbanización. Al igual que en las dos etapas previas, la lógica extensiva de ocupación del territorio hizo que la mancha urbana avanzara hasta límites insospechados, provocando crecientes tensiones entre diferentes usos del suelo. Esto vale para caracterizar la multiplicación de las gattedcomunities en antiguas zonas productivas, 
pero también para explicar la producción de hábitat popular en áreas cada vez más alejadas, en cercanías de yacimientos hidrocarburíferos. Sin embargo, no podemos dejar de un mencionar una contrafuerza, un fenómeno que tuvo como escenario dilecto al centro neuquino: el crecimiento en altura. En el plano explicativo, podríamos decir que este proceso tuvo como punto de partida la salida del régimen de convertibilidad en 2002. La devaluación de la moneda, que multiplicó la rentabilidad de los tenedores de dólares no hizo más que incrementar el volumen de operaciones inmobiliarias, estimulando la construcción de torres: durante la segunda mitad de la década de 2000 se tramitaron 122 proyectos, un tercio de los cuales correspondió a 2010, año que marca el inicio de un proceso de amesetamiento (Rio Negro, 27/12/2010). Esta densificación, que fue acompañada de la elitización, dio a Neuquén una apariencia com-fusa: el centro se volvió cada vez más compacto y homogéneo; mientras que la periferia hizo de la difusión y la heterogeneidad sus principales características (Abramo, 2012).

\section{A modo de conclusión}

Luego de este itinerario por el siglo XX: ¿Qué reflexiones, a la vez, localizadas y deslocalizadas podemos hilvanar?

\section{Imagen 1}

Síntesis de la estructuración socioespacial de la ciudad de Neuquén (19042010)

01.

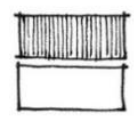

Alimo
Ba

03.
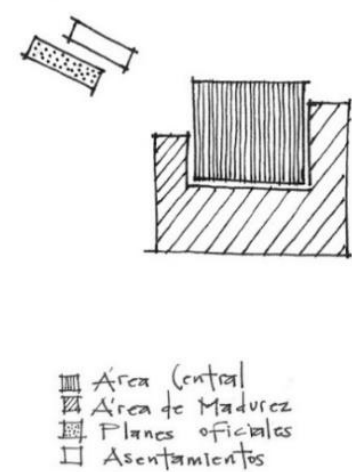

02 .

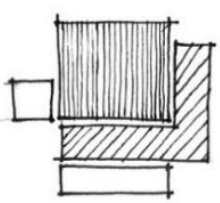

IIIII) Área (entral

II Franja I
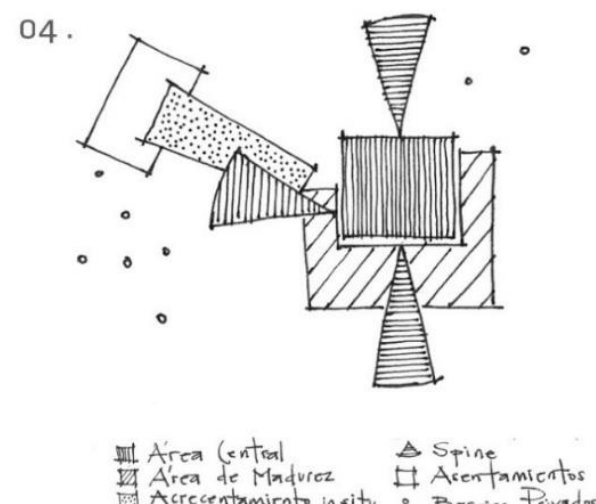

Referencias: 01- Neuquén territoriano (1904-1955); 02-Neuquén Desarrollista I (19551970); 03-Neuquén Desarrollista II (1970-1991); 04-Neuquén Neoliberal (1991-2010)

Fuente: Arq. María Mercedes Martinez (UNRN) 


\section{La segregación urbana desde el tiempo y el espacio. Una aproximación en una ciudad patagónica (Neuquén, 1904-2010)}

Gracias al ejercicio de "triple dislocamiento" llenamos de contenido las dos hipótesis que pusimos en juego a lo largo del trabajo. Con el auxilio de una variada gama de recursos heurísticos, pudimos demostrar la ubicuidad tanto de la segregación como del carácter expansivo de la urbanización neuquina. Claro que ambos fenómenos asumieron diferentes modalidades en el arco temporal escogido. Y es precisamente este dinamismo aquello que nos permitió modelar los límites de una periodización; una que hizo posible que nos aproximemos a las siempre complejas interfaces entre estructura social y espacial. En el "Neuquén Territoriano" advertimos una lejanía social que convivía con una cercanía física, aunque la acción del capital inmobiliario comenzaba a estirar exageradamente los límites de la mancha urbana. El "Neuquén Desarrollista" transitó por un camino de creciente polarización: el par centro-periferia incrementó la distancia espacial entre las clases sociales, al tiempo que la acción del Estado provincial, con su política de vivienda, reforzó el carácter centrífugo del crecimiento de la capital. El "Neuquén neoliberal" tuvo a la fragmentación como su marca indeleble: aunque la brecha social tendió a incrementarse, la distancia física no pareció comportarse del mismo modo. Vemos, en todo caso, urbanizaciones cerradas y asentamientos muy próximos en su localización, aunque separados por fronteras muy difíciles de franquear. Al mismo tiempo, la tónica del mercado inmobiliario, con precios en alza, recrudeció los efectos del crecimiento "hacia fuera", pero también densificó (y elitizó) el área central, dando forma a una renovación claramente excluyente. Los rasgos estilizados de cada una de las etapas pueden encontrarse en la siguiente síntesis gráfica (Figura 1).

Cerremos el texto retomando algunas de las ideas con las que comenzamos el artículo. Aprovechemos el sugestivo planteo de Roy para establecer una apuesta a futuro: toda posibilidad de descentrar la teoría urbana nos obligará a abrir una agenda comparativa, no solo entre las metrópolis del Sur y del Norte, sino fundamentalmente entre urbes de distinto porte. Pensando al interior de nuestro campo académico, y volviendo sobre algunos de los aspectos relevados en la primera sección, esa frontera involucra inevitablemente a las ciudades de tamaño medio. Y es allí donde adquiere relevancia el caso neuquino. Las dimensiones y las fases descubiertas en "el sur del Sur" podrían servir como insumo para llevar adelante lo que Roy define como un "esencialismo estratégico", permitiendo "un pensamiento y una epistemología más dinámicos". El desafío no reside, entonces, en ver en qué medida otras aglomeraciones se ajustan o distancian de lo visualizado en Neuquén. De lo que se trata es de hacer propia una actitud problematizadora que permita “trazar raíces y rutas más complejas” (Roy, 2013: 175), preparando el terreno para narrativas que tengan a la heterogeneidad como punto de partida.

\section{Bibliografía}

AAVV (2004). Neuquén. 100 años de Historia. General Roca: Editorial del Diario Rio Negro. 
Abramo, Pedro (2012). La ciudad com-fusa: mercado y producción de la estructura urbana en las grandes metrópolis latinoamericanas. EURE. Revista latinoamericana de estudios urbano-regionales 38(114).

Álvarez De La Torre, G. (2011). Estructura y temporalidad urbana de las ciudades intermedias en México. Frontera Norte 23 (46).

Ares, S. y Mikkelsen C. (2007). Segregación espacial de la población en localidades menores del partido de General Pueyrredón. 2001. Ponencia presentada en XI Conferencia Iberoamericana de Sistemas de Información Geográfica, Buenos Aires, Argentina.

Auyero, J. y Burbano, A. (2012). Peligro en los márgenes urbanos. Ethnography, $13(4)$.

Auyero, J. yHobert, R. (2005). ¿Y esto es Buenos Aires?". Los contrastes del proceso de urbanización. en D. JAMES (Comp). Nueva Historia Argentina. Violencia, proscripción y autoritarismo (1955-1976). Buenos Aires: Sudamericana.

Bandieri, S. (2005). Historia de la Patagonia. Buenos Aires: Sudamericana.

Bandieri, S.yAngelini, M. (1983). Bases estadísticas para el estudio histórico de la evolución y distribución de la población neuquina. Ponencia presentada en $V$ Jornadas de Historia Económica Argentina, San Juan, Argentina.

Borsdorf, A. (2003). Cómo modelar el desarrollo y la dinámica de la ciudad latinoamericana. EURE. Revista latinoamericana de estudios urbano-regionales 29 (86).

Braudel, F. (1970). La historia y las ciencias sociales. Madrid: Alianza.

Burgess, E. (1924). The Growth of a city: an introduction to a research project.Publications of the American sociological society,18.

Buzai, G. (2003). Mapas Sociales Urbanos. Buenos Aires: Del Lugar Editorial.

Carballo, C. (2002). Buenos Aires y las urbanizaciones cerradas: nuevas formas de apropiación del espacio urbano. En: L. CABRALES BARAJAS (Comp.), Latinoamérica: países abiertos, ciudades cerradas. Guadalajara: Universidad de Guadalajara / UNESCO.

Cervera, F. (1970). Ecología de la ciudad de Santa Fe. Santa Fe: Universidad Nacional del Litoral. 


\section{La segregación urbana desde el tiempo y el espacio. Una aproximación en una ciudad patagónica (Neuquén, 1904-2010)}

Ciccolella, P. yl. Mignaqui (2009). Globalización y transformaciones de la centralidad histórica en Buenos Aires.Centro-h, Revista de la Organización Latinoamericana y del Caribe de Centros Históricos (3).

Ciccolella, P. yL. Vecslir (2012). Dinámicas, morfologías y singularidades en la reestructuración metropolitana de Buenos Aires. RIURB. Revista Iberoamericana de Urbanismo (8).

Colantuono, R. et al (1987). Cartas de oferta del medio para la expansión urbana de Neuquén. Neuquén: Departamento de Geografía, Facultad de Humanidades, UNCo. Cuenya, B. (2018) Consensos y puntos de debate en torno a los conceptos de segregación y fragmentación urbanas. Revista Iberoamericana de Urbanismo (14).

Domeett, G. yKopprio, S. (2007). Análisis de la dinámica del ingreso y su relación con la pobreza. El caso del Aglomerado Neuquén Plottier, Periodo 1993-2005. Ponencia presentada en IX Jornadas Argentinas de Estudios de Población, Huerta Grande, Argentina.

Edelman, A. (1954). Recuerdos territorianos. Los primeros años de Neuquén Capital. Neuquén.

Falcón, L. (2011). Diferenciación socio residencial, una aplicación práctica al espacio urbano del gran Resistencia. Revista Geográfica Digital 8 (15). Recuperada de http://hum.unne.edu.ar/revistas/geoweb/default.htm 1

Ford, L. (1996). A new improved model of latinamerican city structure. Geographical Review 86 (3).

Ford, L. (2003). America's new downtowns: revitalization or reinvention? Baltimore: Johns Hopkins University Press.

Gallucci, L. (2007). Los trabajadores en un lugar de la Republica posible. Prácticas electorales y sectores subalternos em Neuquén a comienzos de la década de 1920". En E. Mases y L. Gallucci, L. Historia de los trabajadores em la Patagônia. Neuquén: EDUCO.

Girola, F. (2008). Modernidad histórica, modernidad reciente. Procesos urbanos en el Área Metropolitana de Buenos Aires: los casos del Conjunto Soldati y Nordelta (Tesis doctoral). Universidad Nacional de Buenos Aires, Buenos Aires.

Goycochea, A. (Dir.) (1984), Proyecto Contribución al estudio de la estructura urbana desde el uso del suelo, Facultad de Humanidades, Universidad Nacional del Comahue. 
Gómez, N. y Natera Rivas, J. (2012). Diferenciación residencial de los aglomerados mayores de la región centro de Argentina. Cuadernos de Geografía 21(1).

Gorelik, A. (2004). La grilla y el parque. Espacio público y cultura urbana en Buenos Aires, 1887-1936.Buenos Aires: UNQ.

Griffin, E. y Ford, L. (1980). A model Of Latin American City Structure. Geographical Review 7 (4).

Howell, D. (1989). A model of argentine city structure. Revista Geográfica (109).

Hoyt, H. (1939). The structure and growth of residential neighborhoods in American cities. Washington DC: Federal Housing Administration.

Iuorno, G. (2004). Un siglo 1904-2004. Neuquén ciudad imaginada... ciudad real. Neuquén: Universidad Nacional de Comahue-Municipalidad de Neuquén.

Janoschka, M. (2002). Urbanizaciones privadas en Buenos Aires: ¿hacia un nuevo modelo de ciudad latinoamericana? En L. Cabrales Baraja. Ciudades cerradas - países abiertos. Guadalajara: Universidad de Guadalajara/UNESCO.

Kaminker, S. (2015a): "Descentrar el estudio de la segregación residencial. Cargas, legados y reflexiones para su estudio en ciudades intermedias de América Latina", Bifurcaciones. Revista de Estudios Culturales Urbanos, $N^{\circ} 15$, Universidad Católica del Maule, Talca, Chile.

La Revista de CALF, “Informe especial: Villas emergencias”, no 86, año 8, pp. 4-5

Lacarrieu, M. (2002). La comunidad: el mundo imaginario en las urbanizaciones privadas en Buenos Aires. En L. Cabrales Barajas(comp.). Latinoamérica: países abiertos, ciudades cerradas. Guadalajara: Universidad de Guadalajara/UNESCO.

Lévy, J. P., \& Brun, J. (2002). “De la extensión a la renovación metropolitana: mosaico social y movilidad. En DUREAU, F. et al. (Comp.), Metrópolis en movimiento: Una comparación internacional, Bogotá, Instituto de Investigaciones para el Desarrollo.

Linares, S. Y Lan, D. (2007). Análisis multidimensional de la segregación socioespacial en Tandil (Argentina) aplicando SIG. Investigaciones Geográfica (44)

Silveira, M. (1988). Estructura urbana de la ciudad de Neuquén en perspectiva diacrónica (Tesis de Licenciatura). Departamento de Geografía - UNCo, Neuquén. 


\section{La segregación urbana desde el tiempo y el espacio. Una aproximación en una ciudad patagónica (Neuquén, 1904-2010)}

Malizia, M., Boldrini, P. y Ruíz Peyré, F. (2018). Las ciudades intermedias del noroeste argentino como espejo de los modelos de desarrollo. Revista Redes, Revista do Desenvolvimento Regional 23 (3).

Mases, Enrique y otros; El mundo del trabajo, Neuquén, 1884-1930, Neuquén, 1994.

Mases, E. y Montes Le Fort, L. (2001). La ciudad del viento... Historias, Arquitectura y Sociedad en el núcleo urbano de Neuquén Capital. General Roca: Publifadecs-UNCo.

Mases, E.et al. (2004). Neuquén: 100 años de Historia. General Roca: Editorial Diario Río Negro.

Massey, D. y Denton, N. (1988). The Dimensions of Residential Segregation.Social Forces 67 (2).

Marcos, M. y Mera, G. (2009-2010). Pobreza Estructural y migración limítrofe: aportes para pensar su articulación espacial en la aglomeración Gran Buenos Aires. Estudios Socioterritoriales (8).

Mertins, G. (2003). Transformaciones recientes en las metrópolis Latinoamericanas y repercusiones espaciales. En J. Luzón, C. Stardel y C. Borges (coords.). Transformaciones regionales y urbanas en Europa y América Latina. Barcelona: Universitat de Barcelona.

Moya, J. (2003). Primos y extranjeros. La inmigración española en Buenos Aires, 18501930. Buenos Aires: Emecé.

Natera Rivas, J. (2005). Factores de la diferenciación socio habitacional urbana en San Miguel de Tucumán. Breves Contribuciones del I.E.G(17).

Natera Rivas, J. (2006). Diferenciación socio residencial del espacio urbano en las capitales provinciales del Noroeste Argentino. Málaga: Mimeo.

Natera Rivas, J. y Gómez, N. (2007). Diferenciación socio residencial en el aglomerado del Gran Santa Fe (Argentina) a comienzos del siglo XXI. Revista Universitaria de Geografía (1).

Padín, N. y Perren, J. (2015). Historia, ciudad y sociedad: antecedentes, problemas y trayectorias. Una mirada desde la Norpatagonia. Coordenadas. Revista de Historia local y regional 2 (1).

Peláez, E., González, L. y Cunha, J. (2008). Dimensiones de la segregación residencial en el Gran Córdoba (Argentina) y comparación con Región Metropolitana de Campinas (Brasil). Carta Económica Regional 20(100). 
Pérez, G. (2018). La conurbación en torno a la ciudad de Neuquén. Perspectiva regional y aportes para el ordenamiento territorial (Tesis de Doctorado en Geografía). La Plata, Universidad Nacional de La Plata.

Perrén, J. (2006). Destino: Neuquén. Migraciones y patrones residenciales en la Norpatagonia (1960-1970). Anuario del Centro de Estudios Históricos Prof. Carlos Segretti, (6).

Perrén, J. (2007), "Migraciones y patrones en el Neuquén aluvional (1970-1991), Estudios Migratorios Latinoamericanos21 (63)

Perrén, J. (2009). Mercado laboral y migraciones en el Neuquén aluvional. Una aproximación a partir de fuentes nominativas. Historia Regional 22 (27).

Perrén, J. (2010). Estructura urbana, mercado laboral y migraciones. Una aproximación al fenómeno de la segregación en una ciudad de la Patagonia (Neuquén: 1960-1990). Miradas en Movimiento (4).

Perrén, J. (2011). Segregación residencial socioeconómica en una ciudad de la Patagonia. Una aproximación al caso de Neuquén (1991). Estudios Socio-territoriales (10).

Perrén, J. (2012). Las migraciones internas en la Argentina moderna. Una mirada desde la Patagonia (Neuquén, 1960-1991), Buenos Aires, Prometeo.

Perrén, J, Pérez, G y Cabezas, S. (2019). Crecimiento en altura en una ciudad intermedia argentina. Neuquén hacia comienzos del siglo XXI. Revista Pilquen. Sección Ciencias Sociales. Vol 22, $\mathrm{N}^{\circ} 3 . \quad$ Recuperado de: http://revele.uncoma.edu.ar/htdoc/revele/index.php/Sociales/article/view/2403 $\not 59087$

Portes, A. y Roberts, B. (2005). La Ciudad Bajo el Libre Mercado. En A. Grimson, Ciudades latinoamericanas: un análisis comparativo en el umbral del nuevo siglo. Buenos Aires: Prometeo.

Prieto, M. (2012): "Diferenciación socio-espacial urbana. El caso de Bahía Blanca, Argentina”, Geografía y Sistemas de Información Geográfica (GEOSIG), Año 4, № 4, Universidad Nacional de Luján, pp. 187-214.

Prislei, L. (2004). Neuquén 1904-2004: imágenes de una ciudad centenaria. Neuquén: EDUCO-Universidad Nacional del Comahue. 


\section{La segregación urbana desde el tiempo y el espacio. Una aproximación en una ciudad patagónica (Neuquén, 1904-2010)}

Recchinide Lattes, Z. (1973) El proceso de urbanización en la Argentina: distribución, crecimiento y algunas características de la población urbana. Desarrollo Económico 12 (48).

Reñe, M. (1994). Estructura interna de Rosario: aplicación de un modelo. Contribuciones Científicas (1).

Roca, Juan (1981). Acción pública y acción privada em La urbanización de la nueva capital del territorio del Neuquén. La sociedad anónima Nueva España.En E. Maida. La ocupación de La tierra publica em El departamento Confluencia después de la campaña del Desierto. Neuquén: UNCo.

Rodríguez, G. (2008). Segregación residencial socioeconómica en la Ciudad Autónoma de Buenos Aires. Dimensiones y cambios entre 1991-2001.Población de Buenos Aires 5(8).

Romero, M. y Goycochea, M. 2016. Tensiones ambientales, desigualdades e imaginarios en la expansión urbana. El caso Neuquino. Recuperado de: http://www.trabajosocial.unlp.edu.ar/uploads/docs/romero goycochea gt 27.pd f.

Roy, Ananya (2013 [2009]). Las metrópolis del siglo XXI. Nuevas geografías de la teoría. Andamios. Revista de Investigación Social 10 (22).

Rubalcava, R. y Schteingart, M. (2012). Ciudades divididas desigualdad y segregación social en México. México: El Colegio de México.

Sabatini, F. (2003). La segregación social del espacio en las ciudades de América Latina. Santiago: Instituto de Estudios Urbanos y Territoriales (PUCC).

Sánchez, D., Sassone, S. y Matossian, B. (2007). "Barrios y áreas sociales de San Carlos de Bariloche: Análisis geográfico de una ciudad fragmentada", IX Jornadas Argentinas de Estudios de Población, Huerta Grande: Asociación de Estudios de Población de la Argentina.

Sassen, S. (1991). The Global City. New York, London, Tokyo. Princeton-New Jersey: Princeton University Press.

Sassone, S. (2009). Geografías bolivianas en la gran ciudad: acerca del lugar y de la identidad cultural de los migrantes. En P. PÍREZ (ed.). Buenos Aires, la formación del presente. Quito: OLACCHI.

Sassone, S. y Mera, C. (2009). Barrios de migrantes en Buenos Aires: Identidad, cultura y cohesión socioterritorial. En B. FRITSCHY (Comp.). Manual de capacitación 
docente: Olimpiada de Geografía de la República Argentina. Santa Fe: Universidad Nacional del Litoral- Ministerio de Educación, Ciencia y Tecnología de la Nación.

Scobie, J. (1986). Buenos Aires del centro a los barrios, 1870-1910. Buenos Aires: Solar.

Silveira, M. (1988). Estructura urbana de la ciudad de Neuquén em La perspectiva diacrónica (Tesis de Licenciatura), Universidad Nacional del Comahue, Neuquén.

Sinigoj, N. Et Al (1982). Carta del medio ambiente y su dinámica en Villa Regina. Boletín Geográfico (11).

Sinigoj, N Et Al (1984). Carta del medio ambiente y su dinámica de Plottier (provincia del Neuquén 1983). Boletín Geográfico 14, pp. 9-84.

Sjoberg, G. (1960). "The pre-industrial city": Past and Present, The Free Press, Glencoe.

Svampa, M. (2001). Los que ganaron. La vida en los countries y barrios privados. Buenos Aires: Biblos.

Sznol, F. (2007). Pensar y construir la ciudad. Reflexiones sobre la producción del espacio urbano de Neuquén. Revista de la Facultad. Estudios Sociales (13).

Sznol, F. (2007aㅡ). Geografía de la Resistencia. Protesta social, formas de apropiación y transformación del espacio urbano en la Argentina (1996-2006). Theomai (15).

Tecco, C. y Valdés, E. (2006). Segregación residencial socioeconómica e intervenciones para contrarrestar sus efectos negativos: Reflexiones a partir de un estudio en la ciudad de Córdoba, Argentina. Cuadernos de Geografía. Revista anual del Departamento de Geografía, Bogotá, Universidad Nacional de Colombia.

T. E. C. H. O. Argentina. 2013. Relevamiento de asentamientos informales 2013. Buenos Aires. Recuperado de: http://www. techo. org/países/argentina.

Torres, H. (1975). Evolución de los procesos de estructuración espacial urbana. El caso de la ciudad de Buenos Aires. Desarrollo Económico 58 (15).

Vapnarsky, C. y Pantelaides, E. (1983). Los pueblos del Norte de la Patagonia 17891957. General Roca: Editorial de la Patagonia.

Vapnarsky, C. y Pantelaides, E. (1987). La formación de un área metropolitana en la Patagonia. Población y asentamiento en el Alto Valle. Buenos Aires: CEUR. 
La segregación urbana desde el tiempo y el espacio. Una aproximación en una ciudad patagónica (Neuquén, 1904-2010)

Vidal Koppmann, S. (2007). Transformaciones socioterritoriales de la Región Metropolitana de Buenos Aires en la última década del siglo XX. La incidencia de las urbanizaciones privadas en la fragmentación de la periferia (Tesis de doctorado). Buenos Aires, Facultad Latinoamericana de Ciencias Sociales (FLACSO).

Recibido: $12 / 06 / 2019$

Evaluado: $22 / 07 / 2019$

Versión Final: 30/08/2019 